\title{
Correlation between critical thinking skills and decision making skills in athletic training and the examination of critical thinking differences across the curriculum
}

\author{
Wanda S. Swiger \\ West Virginia University
}

Follow this and additional works at: https://researchrepository.wvu.edu/etd

\footnotetext{
Recommended Citation

Swiger, Wanda S., "Correlation between critical thinking skills and decision making skills in athletic training and the examination of critical thinking differences across the curriculum" (2005). Graduate Theses, Dissertations, and Problem Reports. 2672.

https://researchrepository.wvu.edu/etd/2672

This Dissertation is protected by copyright and/or related rights. It has been brought to you by the The Research Repository @ WVU with permission from the rights-holder(s). You are free to use this Dissertation in any way that is permitted by the copyright and related rights legislation that applies to your use. For other uses you must obtain permission from the rights-holder(s) directly, unless additional rights are indicated by a Creative Commons license in the record and/ or on the work itself. This Dissertation has been accepted for inclusion in WVU Graduate Theses, Dissertations, and Problem Reports collection by an authorized administrator of The Research Repository @ WVU. For more information, please contact researchrepository@mail.wvu.edu.
} 
Correlation between Critical Thinking Skills and Decision Making Skills in Athletic Training and the Examination of Critical Thinking Differences

Across the Curriculum

Wanda S. Swiger, M. Ed., ATC

Dissertation submitted to the

School of Physical Education

at West Virginia University

in partial fulfillment of the requirements

for the degree of

Doctor of Education

in

Physical Education

Robert Wiegand, Ed. D., Chair

Andrew Hawkins, Ph. D.

Lynn Housner, Ph. D.

Patricia Obenauf, Ed. D.

Vincent Stilger, HSD, ATC

School of Physical Education

Morgantown, WV

2005

Keywords: Critical Thinking, Decision-making, Clinical reasoning, Athletic training, Educational Programs 


\begin{abstract}
Correlation between Critical Thinking Skills and Decision Making Skills in Athletic Training and the Examination of Critical Thinking Differences Across the Curriculum
\end{abstract}

Wanda S. Swiger, M. Ed., ATC

\begin{abstract}
Athletic trainers evaluate the athlete's injury, make decisions regarding injury management, provide first aid and treatment, establish rehabilitation protocols, and evaluate the outcomes of their decisions. To practice effectively, they must think critically and make appropriate decisions. As educators make curriculum changes to improve decision making (DM) in athletic training, instructional methods to develop critical thinking (CT) continues to be proposed as a method to achieve this goal. This idea is based on the hypothesis that there is a DM-CT link, that athletic training students think critically, and that these instructional methods affect critical thinking. Additionally, issues continue to increase regarding the poor performance of students on the National Athletic Trainers' Association Board of Certification Written Simulation (NATABOCWS). Although this may be due to test anxiety, it may also be as a result of students being novices at taking written simulation exams, or if due to the DM-CT link; students do not think critically, students critical thinking is not affected by instructional methods. The correlational methodology compared scores from 11 ATEP seniors' Critical Thinking Appraisal (CTA) and their NATABOC-WS results. Institutions were compared for usage of written simulation evaluations across the curriculum. Finally, 239 college students, 104 non-ATEP students and 135 ATEP students were subjected to a 2X4 MANOVA to identify differences between AT and non-AT majors, as well as identifying differences across all four cohorts. The results indicate that the Point Biserial Correlation as not significant between the NATABOC-WS and the CTA. Athletic training students had little exposure to written simulation evaluation format across the curriculum with only $50 \%$ of the institutions utilizing written simulations across the curriculum and with that only $11 \%$ of the time. The athletic training students did have significantly higher critical thinking skills than did non-athletic training college students; however, differences across cohorts were not significant. Non-athletic training cohort levels were consistent across time until the senior year; while athletic training mean differences in cohorts varied, those usually occurred in the year of formal admission to the athletic training program. Based on the fact that athletic training literature is limited on the topic of critical thinking, the need for additional research is apparent.
\end{abstract}




\section{TABLE OF CONTENTS}

Chapter One - Introduction 1

$\begin{array}{ll}\text { The problem } & 7\end{array}$

$\begin{array}{ll}\text { The statement of the problem } & 7\end{array}$

$\begin{array}{ll}\text { The scope of the study } & 7\end{array}$

$\begin{array}{lr}\text { Assumptions } & 9\end{array}$

$\begin{array}{lr}\text { Limitations } & 9\end{array}$

$\begin{array}{ll}\text { Definition of terms } & 10\end{array}$

$\begin{array}{ll}\text { Significance of the problem } & 11\end{array}$

Chapter Two - Review of the literature 14

$\begin{array}{ll}\text { Critical thinking in education } & 14\end{array}$

$\begin{array}{lr}\text { Critical thinking in allied health professions } & 22\end{array}$

Critical thinking in athletic training $\quad 26$

$\begin{array}{ll}\text { Critical thinking evaluation } & 30\end{array}$

Decision-making in education 32

$\begin{array}{ll}\text { Decision making in allied health professions } & 37\end{array}$

Relationship between critical thinking and decision-making 39

$\begin{array}{lr}\text { Conclusion } & 40\end{array}$

$\begin{array}{ll}\text { Chapter Three - Methodology } & 44\end{array}$

$\begin{array}{ll}\text { Participants } & 44\end{array}$

$\begin{array}{ll}\text { Research Design } & 47\end{array}$

Instrumentation $\quad 51$ 
Written Simulation - National Athletic Trainer's Association Board of Certification Examination

Procedures

Hypothesis

Data Analysis

Chapter Four - Results and Discussions

Introduction

Demographic Results

Demographic Results

Hypotheses

Hypothesis one results

Hypothesis two results

Hypothesis three and four results

Hypothesis one discussion

Hypothesis two discussion

Hypothesis three discussion

Hypothesis four discussion

Conclusion

Chapter Five - Summary Abstract, Conclusions, Recommendations

Conclusions 


\section{APPENDIX LISTING}

Appendix A -Human Subjects RRB Approval 104

$\begin{array}{lr}\text { Appendix B - Information letter } & 109\end{array}$

Appendix C - ATEP Program Demographic Form 111

Appendix D - ATEP Program Director Interview Form 112

$\begin{array}{ll}\text { Appendix E - Student Demographic Form } & 113\end{array}$

Appendix F - Sample Watson Glaser Critical Thinking Appraisal 114

Appendix G - Sample Written Simulation Examination 117

\section{TABLES AND GRAPHS}

Table One - Demographic analysis $\quad 62$

Table Two - Point Biserial Data 65

Table Three - WGCTA Subscale Norms/Descriptives 68

$\begin{array}{ll}\text { Table Four - 2X4 MANOVA Main Effects and Interaction } & 70\end{array}$

Table Five - Univariate Analysis- Fixed variable- Major 71

Graph One - Raw scores for ATEP vs. Non-ATEP students across cohort levels 70 


\section{CHAPTER ONE}

\section{INTRODUCTION AND STATEMENT OF THE PROBLEM}

\section{Introduction}

Critical thinking (CT) has been around since the days of Aristotle and Socrates, when the "Spirit of Inquiry," discerning truth, the cultivation of rational thinking, and the development of democratic citizenship were key ideas of society. Critical thinking is considered a higher level thinking/cognitive skill that centers on reasonable and reflective thinking (Ennis, 1989). Along with the philosophical/historical framework, CT has developed a strong base in educational psychology and is linked to the cognitive theories of Piaget and Gestalt (Gagne, 1977). These theories focus specifically on the thinking process. In the early 1900's John Dewey introduced the idea of CT to education, and Bloom's Taxonomy of Educational Objectives, developed in 1956, is a frequently used educational guide that focuses on the concept of CT being a hierarchical progression of cognition. Since that time, the National Education Goals Panel has advocated CT as an indicator of success in higher education (Banta, 1993). However, studies indicate that students appear to have the greatest increase of CT in their freshman year of college (Dressel \& Mayhew, 1954; Maiorana, 1992), and only with continued "professional" or post graduate higher education (graduate, law, medical schooling) does CT significantly increase (Watson \& Glaser, 1980).

Few CT studies go beyond these CT increases; most of literature does not attempt to ask why the change occurs nor does much of the research suggest possible reasons for this occurrence. Researchers cannot assume that this change occurs because of additional 
education because they have not ruled that increases maybe due to maturation. Only two studies have been completed that target or compare maturation and education. Pascarella (1989) performed a longitudinal study in CT and found that college attendance did increase CT compared to the CT levels of those who did not attend college. Further studies by Pascarella, Bohr, Nora, and Terenzini (1996) offer additional confirmation that full-time students' CT skills have higher increases in the freshman year when compared to part-time students.

Based on this trend in the educational literature, CT skills have also become a hallmark for many allied health professional educational programs. Specifically, nursing now uses $\mathrm{CT}$ as a required outcome measure in evaluation and accreditation of both baccalaureate and graduate nursing programs (National League for Nursing, 1992). Since this mandate in 1992, CT research in nursing has increased and many studies are now looking at CT using the Watson Glaser Critical Thinking Appraisal (WGCTA). Continued research has also led to the development of the California Critical Thinking Skills Test (CCTST) and the California Critical Thinking Disposition Inventory (CCTDI) (Fancione, Fancione, \& Sanchez, 1994). These two newer examinations parallel the WGCTA for evaluating general CT skills. The CCTDI is a discipline-neutral, Likert scale attitudinal inventory that estimates to what degree an individual is likely to think critically, while the CCTST is a multiple choice test that examines the skills necessary to think critically (Bartlett \& Cox, 2002; Fancione, Fancione, \& Sanchez, 1994). Yet, hindering all CT research is the lack of a definitive definition of CT.

A review of the literature by Jones and Ratcliff (1993) indicated as many as five definitions of CT. Robert Ennis's definition of CT is "as reasonable and reflective 
thinking, focused on deciding what to do" (Ennis, 1989, p. 4). This relates to other terms in the literature such as decision-making (DM), problem solving, and creative thinking. Richard Paul's definition of CT focuses on self-directed thinking and follows Bloom's Taxonomy of Educational Objectives (Paul, 1985). Other definitions include terms like: "disposition to act with accordance to reason," "responsible thinking that facilitates good judgment," and the ability to "engage in activity with reflective skepticism" (Jones \& Ratcliff, p. 4.). While it varies from source to source, CT skills appear to have a positive correlation with DM and problem solving skills (Fancione, Fancione, \& Sanchez, 1994; Heinrichs, 2002, Hill, 2002).

Athletic training (AT) is a professional field similar to nursing that requires DM and CT. Because professional DM is a component of AT, it is important for educators to examine this DM-CT link. In addition, athletic training educational programs (ATEP) have based much of their curriculum theory on that of other allied health professions, such as nursing, physical therapy, and respiratory therapy (Delforge \& Behnke, 1999), yet ATEP has only recently begun to investigate $\mathrm{CT}$ in their students and in their curriculum (Fuller, 1997; Heinrichs, 2002, Leaver-Dunn, Harrelson, Martin, \& Wyatt, 2002; Misasi, Davis, \& Shapiro, 2005). The AT curriculum is a competency-based curriculum that focuses on the idea of students learning-over-time. Learning-over-time is the idea that students learn in theory and then learn to apply that knowledge in a problembased learning environment in a variety of situations across the curriculum. Because of educators' desire to increase clinical reasoning and professional DM, allied health education continues to emphasize these ideas within their curriculum. 
$\mathrm{CT}$ in allied health professional education continues to focus on gains made at entry and exit points as well as the relationship between CT, problem-solving, clinical reasoning, and DM. The research focuses on correlation studies and pre-entry and postexit testing of allied health professionals. Although some of the entry-exit studies compare various educational settings (i. e. two-year, four-year, post-graduate, etc.), none of these studies compare CT to non-nursing (or allied health) majors. Therefore, it is difficult to say whether the gains were as a result of the allied health professional education or as a result of additional general education The majority of the research done in AT education has focused on predictors for success in ATEPs (Platt, SammaroneTurocy, McGlumphy, 2001), the examination of learning styles (Coker, 2000), internal and external factors influencing student learning (Clark \& Harrelson, 2002; Laurent \& Weidner, 2001; Lebsack-Wiksten, Patterson, Antonio, De La Cruz, \& Buxton, 1998; Mensch \& Ennis, 2001; and Swann \& Walker, 2001), fostering CT via CT learning objectives and the evidence of CT questions on written evaluations within ATEPs (Fuller, 1997). There have also been discussions of the importance of scenarios, both formal and informal that simulate real-life situations (Peer \& McClendon, 2002). In addition, there have been some attempts to discuss the importance of cognitive learning processes within AT students (Clark \& Harrelson, 2002) as well as learning theories to increase students' decision-making abilities (Heinrichs, 2002, Peer \& McClendon, 2002).

While research has found that AT students across the curriculum (random cohorts with varying GPA and number of hours in the training room) have a predisposition to think critically (Leaver-Dunn et al, 2002), the researchers did not examine CT skills across the curriculum. Another study examined changes in CT skills in AT students as a 
result of different teaching methodologies (Walker, 2002), but stopped short of examining the entire curriculum's effect on changes that may be occurring. While nursing literature has focused on entry-exit or pre-post data, in the AT literature there has not been any research to date that has identified any differences or changes in CT skills between cohorts within an ATEP curriculum.

Although the research on $\mathrm{CT}$ is beginning in the area of AT, there is still a question concerning CT importance. Is there any link between CT and DM within AT? The National Athletic Trainer's Association Board of Certification (NATABOC) has been evaluating professional DM skills on the national athletic training entry-level examination since 1985 (Denise Fandel, personal communication 14 January 2004). The national examination is comprised of three parts: the written or multiple-choice section, the practical or oral section and the written simulation. The written simulation portion of the NATABOC examination assesses "professional judgment and decision making" (Annual Examination Report, 2001). Thus, it evaluates the examinee's abilities to assess and make a suitable decision on any given situation. Prospective athletic trainers are presented with a written scenario, given several options, and they must choose only the essential responses for the scenario (Castle Worldwide, Inc., 1999).

Though the written simulation has been validated for professional DM, based on the six domains of athletic training (AT), prevention of athletic injuries, evaluation and recognition of athletic injuries, first aid and emergency care, rehabilitation and reconditioning, organization and administration, counseling, guidance, education and professional development, (Castle Worldwide, Inc., 1999), it has not been validated for examining CT skills in AT. Moreover, there continues to be a low pass rate (mid 50's to 
low $60 \%$ ) for those attempting the written simulation portion of the NATABOC examination for the first time (Annual Examination Reports, 1999, 2000, 2001, 2002, 2003). Though students are being tested with CT questions (based of Bloom's taxonomy) within a Joint Review Commission in Athletic Training (JRC-AT) curriculum (Fuller, 1997) and the NATABOC certification examination has similar CT based questions, only one research study has investigated a correlation between CT skills (using the CCTST) and DM skills (using the NATABOC-WS) (Misasi, Davis, \& Shapiro, 2005) and there have not been any studies indicating to what extent, if any, ATEP programs are using written simulations (similar to the NATABOC-WS) to evaluate their students. Furthermore, there have not been any studies showing changes or differences in CT skills across the ATEP curriculum. In the absence of literature in AT, it does appear that AT as a profession identifies the importance of CT within the field; however, this idea seems to be based on allied health literature which identifies positive but moderate to weak correlations between CT and DM. Ironically, there have only been three other studies identifying correlations of CT and DM within the allied health field. All three correlation studies utilized the WGCTA and a comparable simulation type examination similar to the NATABOC-WS (Brooks \& Sheppherd, 1999; Girot, 2000; Hill, 2002). Therefore, important research questions for AT educators include: 1) Is there a correlation between $\mathrm{CT}$ and DM in AT? 2) Do educators use a written simulation to evaluate decisionmaking across the ATEP curriculum? 3) Is there a difference between AT majors and non-AT majors in CT during the undergraduate curriculum? 4) Does the current, mandated outcome-based curriculum increase CT skills across cohorts? 


\section{The Statement of the Problem}

\section{THE PROBLEM}

The purpose of this study is to determine if there is a relationship between CT and DM in AT students. In addition, the study will determine to what extent accredited AT programs use written simulations as a primary evaluation tool to evaluate DM across the ATEP curriculum. Furthermore, this study will examine differences in CT of AT students across cohorts within the ATEP curriculum and if differences do occur, determine if there is a larger increase among AT versus non-AT majors.

\section{The Scope of the Study}

For the correlation/descriptive portion of the study, the researcher examined the relationship between CT and DM. To determine if there was a relationship between CT and DM in AT students, the study was delimited to a sample of convenience. The participants of this study were college senior AT students from accredited ATEPs within the state of West Virginia. The correlation study had 11 seniors who participated and were eligible to take the national exam. These seniors attended four ATEP's within the state of West Virginia that were accredited by the Commission on Accreditation of Allied Health Education Programs (CAAHEP) schools. The sample population included students from private and public institutions, of Division I and Division II status, thus controlling for variables related to the type of education/schooling participants may be receiving. To examine CT, participants completed the Watson-Glaser Critical Thinking Appraisal (WGCTA) during the final month of the final semester of their senior year of college. To examine DM, these senior ATEP participants, upon completion of the NATABOC examination (April test date), were supposed to report only their written simulation score to their ATEP director. Following the reporting of pass/fail status, the 
ATEP director forwarded all scores from seniors who had volunteered their score; along with the AT program demographic sheet indicating use of written simulation evaluations within their ATEP curriculum for their respective program. Following the program demographic supplied by program directors, the researcher interviewed each ATEP director to confirm usage of written simulations within each program, credit hours required, etc. Each program director submitted ATEP course syllabi indicating specific evaluation techniques used for each AT course using written simulations, as well as ATEP program exit-examination procedures using written simulations. This aided the researcher in determining the extent to which written simulation examinations are utilized across the curriculum, if they are used only during the senior exit-examination, or if they are used at all within the ATEP curriculum.

The second portion of the study was a cross-sectional descriptive design again delimited by a sample of convenience. This study focused on differences in CT skills across cohorts (freshman, sophomore, junior, senior) within the curriculum. Participants of the target group included athletic training students across all four cohorts from these same four CAAHEP accredited AT programs within the state of West Virginia. The students classified as AT students were currently enrolled in the ATEP or were currently in the application process to enter the ATEP. There were approximately 34 participants per cohort across the four institutions and a total $N=135$. The comparison group, included a variety of majors who were not enrolled in ATEP's, but were enrolled in general education or core elective courses at three of the four institutions. This was done in an attempt to provide a non-ATEP sample from each institution. One institution's elective coursework was not formatted with cross cohort populations and scheduling 
conflicts did not allow the researcher to sample the institution's non-ATEP group. Thus, the control group participants came from students enrolled in general education classes and had an average of 25 students per class, each contained a cross-cohort population with an average of 26 students per cohort. Therefore, the number of participants for the comparison group was $N=104$ non-ATEP majors.

All participants completed the WGCTA during the last several weeks of their second semester of their cohort year. All sophomore, junior, and senior cohorts from the ATEP students have been admitted into the program while the freshman ATEP cohort students were in the process of applying into the ATEP program. In addition, some students applying into an ATEP were from upper level cohorts and therefore, cohorts were defined by semester hours completed versus years in college. This is important in defining cohort and therefore must also be investigated. The comparison group, from the general education courses, which included all four cohorts, were also investigated on the basis of semester hours completed.

\section{Assumptions}

1. The WGCTA is reliable and valid measure of general CT skills.

2. The primary researcher is skilled at administering the WGCTA.

3. Due to a desire to become certified, AT students will have a strong desire to perform well on the NATABOC written simulation.

4. The NATABOC written simulation is a reliable and valid measure of decisionmaking skills in AT.

\section{Limitations}

1. Participants in the study will only represent the West Virginia college population 
of schools accredited by the Commission on Accreditation of Allied Health Education Programs (CAAHEP). Therefore, the results of the study may not be able to be generalized to other AT students from colleges and universities across the nation.

2. Convenience sampling will be used and may, therefore, provide threats to external validity.

3. Because this study is using a cross-sectional design, differences between groups may be as a result of cohort differences rather than the passage of time; therefore may be a threat to internal validity.

\section{Definition of Terms}

Cohort is defined by college semester hours completed and classified as: Freshman $=0-30$; sophomore $=31-60$; Junior $=61-90 ;$ Senior $=91+$.

Critical thinking is defined as a complex cognitive skill that centers on reasonable, reflective thinking that focuses on deciding what to believe or do (Ennis, 1989).

Critical thinking abilities include: defining a problem, recognizing assumptions, determining facts based on information retrieved, interpreting facts given the information provided, and finally, distinguishing between applicable and unrelated information for a given situation (Watson \& Glaser, 1980).

Decision-making is defined as the ability to evaluate a situation and make the appropriate judgment, followed by taking the most appropriate action (NATABOC Test Development, 1999).

Decision-making skills are defined as the ability to state a problem, state the items obstructing the problem, identifying the alternatives for overcoming these items, examine 
the alternatives, rank the alternatives, and, finally, choosing the best alternative to achieve the appropriate outcome (Beyer, 1984).

Problem solving is defined as the ability to identify a problem, hypothesize solutions, test these solutions, choose the best solution, and, finally, apply this solution to the problem (Beyer, 1984).

Clinical reasoning is defined as the process used by medical professionals to make assessments, diagnoses, and therapeutic decisions (Payton, 1985).

Athletic training is defined as an allied health profession with a concentration in prevention of athletic injuries, evaluation and recognition of athletic injuries, first aid and emergency care, rehabilitation and reconditioning, organization and administration, counseling and guidance, and education and professional development.

\section{Significance of the Problem}

$\mathrm{CT}$ in allied health professional education continues to focus on gains made at entry and exit points as well as the relationship between CT, problem-solving, clinical reasoning, and DM. However, the majority of the research done in AT education has not focused on CT skills at any one point within the curriculum, nor has AT research examined why CT is important to the field. Although research has examined that AT students across the curriculum (random cohorts with varying GPA and number of hours in the TR) have a predisposition to think critically (Leaver-Dunn et al, 2002), the researchers did not examine CT skills across the curriculum. Another study examined changes in CT skills in AT students as a result of different teaching methodologies (Walker, 2002), but stopped short of examining the curriculum's effect on changes that may be occurring. Nursing literature has focused on entry-exit data, but in the AT 
literature, there has not been any research to date that has identified any changes or differences in CT skills at entry-exit or across each cohort within an ATEP curriculum. Finally, only one study in AT has examined if CT and DM in AT does exist. This study, by Misasi, Davis, and Shapiro (2005), indicates there is no correlation between the NATABOC-WS and the CCTST. Other correlation studies in the allied health professions indicate weak to moderate correlations (Brooks \& Sheppard, 1999; Girot, 2000; Hill, 2002).

As many educational programs move toward curricular changes to improve students DM skills, the focus on improving higher level thinking skills, e.g. CT, appears to be a current trend in achieving this goal. While nursing and other allied health fields have looked at and found a relationship between CT skills and DM, AT education has not established this relationship between $\mathrm{CT}$ and DM in AT. Therefore, the idea of increasing student DM via increasing CT is based on a hypothesis that there is a positive relationship between the two. Thus far, this relationship has not been identified in any of the AT literature.

Additionally, the NATABOC-WS examination has been examining the DM skills of AT students since its inception in 1985; however, according to the Annual Report for Testing for the years 2002, 2001, 2000, and 1999, the pass rate for the students taking the written simulation NATABOC examination was $54.05 \%, 54.74 \%, 55.17 \%$, and $54.20 \%$, respectively. Finally when looking at the overall pass rate, a total of $36.18 \%$ of all candidates passed all three portions of the national certification examination on the first attempt in $2002,33.94 \%$ in $2001,36.58 \%$ in 2000 and $31.26 \%$ in 1999 . This low percentage overall leads to questions of how well ATEP programs are preparing their 
students to be entry-level athletic trainers. Additionally, how well are ATEPs preparing students for clinical decision making, as well as for the national examination? Currently there has been no literature to date indicating if ATEP's utilize written simulations with the curriculum.

Results from this study may lead to verifying a positive relationship between CT and DM within the field of AT. It may also lead to increased knowledge in the field of AT education and may shed some light into whether CT differs as a result of an ATEP curriculum, or if there is only a difference as a result of higher education by all participants. It is the intent that this gained perspective may eventually increase ATEP educators' abilities to improve CT and DM skills in AT students across the ATEP curriculum. This study will also provide feedback to ATEP educators regarding their use of written simulation examinations within ATEP curriculums. If the study indicates low usage of this type of examination, it is the hope of this researcher that ATEP program directors and faculty will identify the need for the written simulation to become a primary evaluation tool within their curriculum thus increasing student exposure to this type of testing, and providing students' the opportunity to become more comfortable with this type of evaluation. This may give rise to developing a better overall clinician/entry-level AT, that has an increased ability to make professional, sound, clinical decisions. 


\section{CHAPTER TWO}

\section{LITERATURE REVIEW}

The purpose of this chapter is to provide a review of the pertinent literature surrounding the area of critical thinking and decision-making within athletic training. Thus the chapter will evolve from a discussion on CT, CT within general education, CT within allied health education and CT within ATEP education. Finally the discussion of decision making within allied health and its correlation to CT will be discussed.

\section{Critical Thinking in Education}

The idea of critical thinking (CT) has been around for centuries. In addition to a theoretical philosophy, CT has a strong base in educational psychology, specifically, cognitive theory. This theory focuses on the thinking process. Gestalt psychology, which says all persons have an innate tendency to organize information received from the environment, and Piaget's Theory of Cognitive Development that states this development moves from simple to complex and concrete to abstract are also a strong part of the framework of CT (Maiorana, 1992). Bloom's Taxonomy of Educational Objectives (1956) is a frequently used educational guide that focuses on the concept of CT that progresses the hierarchy of cognition. These categories include behaviors from simple to complex, concrete to abstract, basic cognitive skills to "higher order thinking" skills: knowledge, comprehension, application, analysis, synthesis, evaluation (Bloom, 1956).

One can relate the taxonomy to AT in the following way:

1. Knowledge: the ability to recall specific information, e. g., label the parts of the heart, etc. 
2. Comprehension: understanding or perceiving information, an example: translate a sentence into a correct statement using medical abbreviations.

3. Application: Utilizing information in a certain manner, attention to detail, e. g., explain why the Lachman's test is a better anatomical position to test the integrity of the anterior cruciate ligament versus the anterior drawer test, etc.

4. Analysis: Breaking down of information from its whole to its parts; an example: detect what grade concussion the athlete has.

5. Synthesis: Combining parts to make a whole; an example: given a yearly budget, create a training room and a list of yearly supplies.

6. Evaluation: making judgments about value; an example: assess and evaluate a knee injury.

Although many have criticized Bloom's Taxonomy as a framework for CT, it is important to remember its objective. Created as a hierarchy of cognition or levels of thought, this was only to be a guide to assist educators in incorporating educational objectives into a curriculum. It is not, however, the definition nor the theoretical framework of CT. It is merely a tool to assist in incorporating and developing "higher order thinking," simple to complex thought, and concrete to abstract cognitive skills to learners (Bloom, 1956). The theoretical framework continues to be fine tuned despite all the controversy of the definition of CT.

Much of the CT literature is wrapped around the definition controversy. How do we as educators define CT? How do we as researchers investigate CT? Ennis (1989) defines $\mathrm{CT}$ as the reasonable, reflective thinking that focuses on deciding what to believe or what to do. Cairns (2000) quoted Chaffee's definition as active, purposeful and 
organized cognitive structures that we used to examine our own thinking in an attempt to clarify and improve our understanding. Watson and Glaser (1980) view CT as a composite of knowledge, skills, and attitudes. In a review of CT literature by Jones and Ratcliff (1993), the authors listed five different definitions of CT. One includes Robert Ennis, while the others include Richard Paul (disciplined, self-directed thinking), J. E. McPeck (skill to engage in activities with reflective skepticism), Siegel (an individual who has the ability to assess via reasoning), and Lipman (skillful, responsible thinking that facilitates good judgment). In essence, CT can be thought of as an array of thinking skills used to help make everyday decisions (Schwager \& Labate, 1993).

Ultimately, due to the complex skill of CT, any definition is controversial. However, in the midst of this controversy of a true definition, the fact remains that CT can be recognized and therefore, researched. There appears to be some general principles of CT that have a large range of applicability (Tsui, 1998).

Dressel and Mayhew (1954) recognized several skills related to CT and define problem solving as the ability to define a problem, the ability to select pertinent information for the solution of that problem, the ability to recognize stated and unstated assumptions, the ability to formulate relevant hypotheses, and the ability to draw conclusions and evaluate the validity of assumptions and hypotheses. Beyer (1984) identified the skills of CT as the ability to distinguish between known facts and beliefs; determining the reliability of a source; determining the accuracy of a statement; distinguishing between known truths versus things that are proven false; discerning between relevant and irrelevant information; discovering bias; identifying assumptions, 
both stated and inferred; identifying ambiguous claims; recognizing inconsistencies within a path of reasoning; and determining the strengths and weaknesses of an argument. When we refer back to Bloom's Taxonomy, CT involves "higher order thinking." These skills appear necessary for all professionals. Within a career, workers are expected to use their knowledge and skills to adapt to changes in their work environment (Miller, 1990). While many now have accepted that the cognitive/educational psychologists have determined "what" the best possible definition might be (Refer to Ennis, 1989), the philosophers argue that they are better equipped to determine "how" CT should be taught. In looking at how $\mathrm{CT}$ is taught, there are additional terminologies that are used interchangeably with CT.

Comparisons of CT to other skills related to higher order thinking skills include problem solving, decision-making, and metacognition. Problem solving is a cognitive process focused on solving a goal when there does not appear to be a solution (Mayer \& Whittrock, 1996) and includes specific tasks: identify the problem, hypothesize a solution, test the hypothesis, choose the best solution for the problem, and apply the best solution to the problem (Beyer, 1984). Decision-making (DM) refers to the choices made due to external or internal stimuli (Parker, 1984). Skills of decision-making include: state the desired goal; state the known obstacles; identify alternatives for overcoming these obstacles; examine all the alternatives; rank the alternatives; choose the best one (Beyer, 1984). Professional DM will be discussed in more depth later in the chapter. Metacognition refers to being aware of our own thinking or the act of active monitoring of our thought processes (Marzano, et al, 1989). 
Another issue in the discussion of CT is whether or not CT is generalizable; can CT transfer from one subject to another or is it subject-specific? This is also a question in the problem-solving/decision-making literature. Mayer \& Whitrock (1996) discussed problem-solving transfer and report that transfer does occur from one task to another task. It may be automatic if it is a similar task or uses part of the old task to solve the new task. However, it requires a conscious effort when the tasks are not similar. Within Gestalt psychology, general skill transfer occurs when a student uses one strategy to complete a task and can then use it to perform a different task in a different subject area (Mayer \& Whittrock, 1996). In athletic training this would be similar to understanding the evaluation process as it applies to the knee and then using the same strategy to perform an evaluation of the elbow. These are similar tasks that vary in subject matter. A students' familiarity of a subject plays a crucial role in that student's performance on thinking tasks within that area (Jones \& Ratcliff, 1993). Would it not seem rational that by teaching these cognitive skills in one subject, then one could use those same cognitive skills in another subject?

According to the Jones and Ratcliff review (1993), Ennis and others support the idea that general principles of CT can be transferred to new situation. In this same review, for example, West Virginia University used a "Guided Design" approach for their engineering program, and this program has been successfully used in nursing, counseling and others. However, McPeck argued that thinking is always about a subject and thus thinking skills cannot be detached from that subject, and as such CT must vary from subject to subject (Jones \& Ratcliff, 1993). There is no evidential support for this. 
However, it may be vital when examining each subject, to also look at CT within each domain.

While the cognitive domain is the main focus for many when discussing CT, athletic training educators must also identify the effect of CT on psychomotor domain. In Graber's review of literature in 2000, there is little discussion of student cognition, and no discussion of $\mathrm{CT}$ in physical education (PE). There is an open slate in regards to $\mathrm{CT}$ in PE; to date, the literature has addressed $\mathrm{CT}$ in the traditional classroom and not gymnasiums. Leaders in the field of PE continue to focus on ways to incorporate CT into PE.

One route may be to identify Harrow's Taxonomy of movement. Harrow has developed a parallel taxonomy to Bloom's, focused on the psychomotor domain. This includes: involuntary movement (reflexes); basic movements (locomotor skills); perceptual abilities (hand-eye and foot-eye); physical abilities (endurance, strength); skilled movements (sport skills), and non-discursive communication (Davies, 1976). Within the psychomotor domain there is a progression from concrete to abstract movements, simple to complex movements. In addition, McBride (1992) defines CT in $\mathrm{PE}$ as reflective thinking used to make reasonable decisions about movement and movement tasks. Not only should PE educators focus on this psychomotor domain to improve skill acquisition, but there is also a trend to focus on thought process behind movement, the cognitive domain.

McBride (1992) provides a model for teaching CT in PE. According to this model, for CT to occur, the learner must be able to inquire. Only through this process can CT skills be activated. While in this inquiry state, the learner does not passively 
accept information, but begins the process of seeking a solution. The teacher, willing to foster $\mathrm{CT}$, must create opportunities for this cognitive dissonance to occur. The learner then assumes the responsibility for learning, and the teacher is a monitor or guide. Once this has occurred, the student begins to organize and articulate thoughts. The student is now able to use these ideas to make judgments. Finally, the student is able to test these thoughts and ideas by focusing on cognitive and psychomotor outcomes. This is not simply trial and error; the learner is methodical in his/her choices, analyzing each step, and modifying information or movement to obtain the desired outcome. For example, in AT, students are taught the psychomotor skill of how to perform a Lachman special test for the integrity of the anterior cruciate ligament of the knee. To teach the skill students must comprehend anatomy, relevance, mechanism of injury, and the "how to" of the skill. Following this instruction, the instructor must provide learning opportunities for the student to experience what a positive and negative test are. Finally there should be scenarios for the student to apply the use of the special test in an actual injury evaluation. McBride (1992) also stressed the need for students to be aware of the thinking process and actively monitor it; this is termed metacognition. Within PE, teachers may be already incorporating $\mathrm{CT}$ into their gymnasium, without even knowing it. By having students focus on decisions that affect the success of a skill, teachers are encouraging thinking skills. Because motor skills are a series of information processing tasks, students must engage in some form of CT to learn, accomplish, and succeed at these movements. General models exist, but unless domain specific, research has shown that non-specific domain techniques are not as effective (McBride). 
Most colleges regard CT as an important component of professional development. Most physical education teacher education (PETE) programs are encouraging CT skills and DM skills, because of the belief that it is paramount in student teaching practices. It is thought that in this capstone experience, DM abilities are promoted and enhanced. The university supervisor and the cooperating teacher must nurture DM skills. These skills may not develop on their own. Student teachers are not thought to be quality teachers because they put in the time; therefore specific feedback is required.

Developing DM skills is important because these future teachers must sort through a vast amount of teaching material and information to determine their usefulness and to decide what effective techniques can be used to present the content. In addition, these future teachers must be able to set appropriate goals and objectives, as well as evaluation techniques, while at the same time, monitor, critique, and modify those strategies that are effective and those that are not. Sometimes these skills may occur at the end of a lesson; however, sometimes these skills must occur within the lesson. Ultimately, student teachers need assistance in developing these DM skills within the teaching context (Ocansey, Chepyator-Thompson, \& Kumate, 1992).

One study done within PE has focused on modifying teacher behaviors to promote $\mathrm{CT}$ in PE. However, in this study, the teachers' behaviors were examined and compared pre and post an intervention course designed to increase CT. This was done using the CTPE model created by McBride and the use of video to tape each lesson. Student CT gains were not tested (Donnelly, Helion, \& Fry, 1999). The primary research done in PE on CT has come from the movement education model (Donnelly et al, 1999), but again most of these studies address teacher behaviors not student outcomes. Other studies 
include focusing on teachers and teacher planning; novice versus expert teachers' planning/decision-making abilities. These will be discussed later in this chapter.

Within PETE, much of the research on novice and expert teachers has led educators to the rationale of the importance of producing an effective teacher. Part of that rationale is the novice teacher's ability to adapt a lesson to the environment/gymnasium to best suit the students, the teacher and the learning objectives. The ability of a teacher to adapt to the environment and create a positive learning atmosphere within a classroom/gymnasium is key to effective teaching and positive student learning outcomes.

\section{CT in Allied Health Professions}

The development of CT is one of the global goals advocated by many allied heath professional programs. Many medical and allied health curriculums have utilized an entry and exit procedure for testing CT in the curriculum. Scott, Market, and Dunn (1998), used the WGCTA to measure medical students upon entry and again near the end of the third year of schooling. There was no significance in gender comparisons of scores; however, there was a significant increase in total class scores. However, there was no correlation between WGCTA scores and students performance within the clinical clerkship. This might be explained because of the lack of a reliable and valid evaluation technique. There was limited correlation between the CT scores and the scores from an external medical licensing board. This could be because the researchers only looked at one subtest to compare to the licensure examination. Finally, attrition occurs due to survival of the fittest... by the third year of medical school, only the students with the 
highest GPA remain. Thus, Scott et al. (1998) concluded that the WGCTA should be used as a predictor for academic success and not clinical abilities.

Slaughter, Brown, Gardner and Perritt (1989), evaluated a problem-solving model to determine if it could assist first-year physical therapy (PT) students in developing more effective problem solving skills. Evaluation instrument included a pre and posttest of the CTA and posttest feedback from a questionnaire. The participants included 31 first-year PT students entering into a four-week clerkship. Random sampling placed them into a control group, where no pre- or post-clerkship meetings took place nor did the students discuss their case studies with their clinical instructor, the experimental group, where there was a pre- and post-clerkship meeting and in depth discussion of the case studies with the clinical instructors. After analyzing the questionnaire, the problem-solving model was found to be useful and effective for both the students and the clinical instructor. However, due to the extremely high pre-test CTA scores, the model did not show significant gains in $\mathrm{CT}$, but, in fact, for some students, showed a regression toward the mean. As in the medical school study, high GPA could be a limitation of the study. Similarly, other allied health fields are finding similar problems. In a study done by Miller, Sadler, Mohl, and Melchiode (1991), the focus was on complex thinking patterns of psychiatric practice clinical practices. The clinical practices of medicine and psychiatry require complex cognitive skills. Students' medical knowledge should be based on how well they are able to use that knowledge practically. It is then important to identify clinically relevant cognitive processes and determine how they can be taught in medical education. Using Bloom's Taxonomy, the researchers evaluated multiple-choice tests identifying cognitive levels of test questions on undergraduate and postgraduate 
examinations and determined the relevance of these examinations to the cognitive processes involved in clinical psychiatric practice. Using an undergraduate examination and a standardized post graduate examination, three judges reviewed the examinations to find the following results: $57 \%$ of the questions from the undergraduate exam and $79 \%$ of the standardized exam were in the first level of Bloom's taxonomy; $14 \%$ and $8 \%$, respectively for the second level; $29 \%$ and $10 \%$, respectively, were rated at level three; only one question on the standardized exam was rated on level four, and there were no level five or six rated questions on either exam. Due to the lack of higher-level items on the examinations the hypotheses could not be fully examined. Ultimately, medical students are expected to make clinical decisions requiring problem-solving skills, yet they are not evaluated on them.

The nursing literature has seen a significant increase in the $\mathrm{CT}$ research in the last several years. This is due to the mandate by the National League of Nursing in 1992 that requires nursing programs to evaluate CT. Thus many programs perform an entry and exit examinations of CT for each individual within each cohort. From 1987 to 1990, a Hickman's review of the literature (1993) indicates the use of the WGCTA more then any other test to date. The WGCTA was utilized 21 times, the Cornell CT test twice; other types of tests like the Miller's Analogy Test were used sparingly. The WGCTA was probably used most often because of its definition of CT paralleling the nursing process (Hickman). Shortly after this review, the California Critical Thinking Skills Test (CCTST) and the California Critical Thinking Disposition Inventory (CCTDI) were developed. The CCTDI is a discipline-neutral, likert scale attitudinal inventory that estimates to what degree an individual is likely to think critically, while the CCTST is a 
multiple choice test that examines the skills necessary to think critically (Bartlett \& Cox, 2002; Fancione, Fancione, \& Sanchez, 1994). Although these tests have been proven valid for testing $\mathrm{CT}$, neither has been utilized in comparing or correlating $\mathrm{CT}$ with $\mathrm{DM}$. What's more, although not specifically investigating the differences between the CCTST and the WGCTA within AT, Walker (2002) found no significant difference between groups when CT was assessed due to the writing intervention.

Early research indicates inconsistencies in CT gains within nursing students. Sullivan (1987) and Bauwens and Gerhard (1987) determined there was no significant difference between entry and exit scores of nursing graduates. Yet Gross, Takazawa \& Rose (1987) and Miller (1992) found significant increases in associate and baccalaureate nursing students from entry to exit. Vaughan-Worbel, O'Sullivan, and Smith (1997) found that $\mathrm{CT}$ was higher at entry for older students and higher upon entry for students who had a previous degree. All these studies used the WGCTA. These studies were longitudinal in that they looked at sophomores entering into the nursing program and the same students as seniors exiting the program. However, these studies did not look at freshman and junior levels nor did they compare nursing with non-nursing majors. Thus it is uncertain if these students had lower CT scores upon entry and it is unclear if the nursing curriculum was the sole reason for the increase in CT upon graduation.

Using the CCTST and the CCTDI, McCarthy, Schuster, Zehr, \& McDougal (1999) examined if nursing students' increased CT skills and if nursing students had a disposition to think critically. In this cross-sectional research design, the researchers compared CT abilities at entry (sophomore) to exit (senior) nursing students. This increase indicated a statistically significant difference from sophomore to senior year in 
CT skills. Another cross-sectional design used both tests to examine all four cohorts (a snapshot in time) and although there was no statistical significance, the mean scores for the CCTST did show an increase across all but one cohort. The junior or year three cohort mean score did not increase (Profetto-McGrath, 2003). Bartlett and Cox (2002) also used the CCTST and the CCTDI to evaluate physical therapy students. This was a longitudinal study over one academic year that included a pre and post-test and one final examination following the clinical experience. The results indicate significant gains in both tests, with the greatest gains of CT skills occurring after the clinical experience. However, again as in the nursing studies, there was no control group or non-physical therapy majors to compare the increases. Thus we know there is an increase in physical therapy students CT but how do we know the increases are as a result of their specific training as a physical therapist?

\section{CT in Athletic Training}

Athletic training is an allied health field; a complex discipline that involves prevention, recognition, emergency treatment, and the follow up rehabilitation of the injured athlete. Certified athletic trainers (ATC) are responsible for providing and coordinating medical services to athletes and for setting up policies and procedures allowing those services to take place. Looking at the educational background of an ATC, one can identify two domains: cognitive and psychomotor. Within the cognitive domain are the basic knowledge, comprehension and higher order thinking skills. ATC's have a strong foundation in anatomy, physiology, kinesiology, biomechanics, athletic injuries (including prevention, recognition, rehabilitation and assessment). Within this coursework are opportunities to address all levels of cognition. Within the psychomotor 
domain, there are basic competency skills that require hours of practice to perfect a skill. How to perform a special test, how to tape an ankle, how to measure range of motion, how to illicit reflexes; these skills are critical to an ATC's effectiveness. Although these are identified as two separate categories of learning with two different types of outcomes, they must not be viewed as mutually exclusive. In order for an ATC to perform a complete assessment of an injury, both the cognitive and psychomotor domains must work hand-in hand.

Knowing the needs of students who are becoming professional ATC's and combining that knowledge with the accredited curriculum one must follow, the curriculum becomes a kaleidoscope, where many forces and ideas must come together to yield one solution. The questions a curriculum coordinator must focus on become: should CT be used as yet another pre-admission criteria for AT? To what extent do athletic trainers need or use clinical reasoning skills? How do we promote CT within the athletic training curriculum? Do we test for higher level thinking skills? Do we need a subject specific $\mathrm{CT}$ instrument to adequately promote and test $\mathrm{CT}$ in athletic training (AT)? It is the hope of this author that the results of this study answer some of these questions.

According to Wall (1954), who compared Scholastic Aptitude (SAT) scores, high school grade point average (GPA), and first semester college GPA with CT scores, there appears to be a positive correlation between one and the other. A student with a high GPA, high school or college, or a high SAT score would likely have a high CT score. Both a high GPA and a high SAT were not required. Platt, Sammarone-Turocy, \& McGlumphy (2001) determined pre-admission standards for entry level AT programs and 
five other allied health programs. The study reviewed over 373 student's records. Overall, high school GPA and SAT verbal scores were indicative of college success (high college GPA). College GPA has a positive correlation with testing success on the national certification examination. Persons having a lower GPA are less likely to pass the written portion of the NATABOC certification examination then those having a higher GPA (Draper, 1989). Moreover, there appears to be a solid foundation for GPA, SAT and ACT scores predicting student success in ATEPs and in success rates for passing the NATABOC examination.

Furthermore, there seems to be a relatively weak tendency for AT students to have a predisposition to think critically. Ninety-one students from three ATEPs were administered the CCTDI where the overall mean indicated a general but mild trend toward CT. There were no relationships between the CCTDI and age, gender, ethnicity, cohort, cumulative GPA, completed semester hours, or clinical experience hours (LeaverDunn, et al, 2002). While CT dispositions appear to be stable over time, CT skills appear to improve over time with some form of structured education (Fancione, et al, 1994).

Additionally, Fuller (1997) attempted to verify whether CT objectives were being met within the Commission on Accreditation of Allied Health Educational Programs (CAAHEP) Accredited curriculum. Thirty institutions were surveyed with a 43\% return rate. Using Bloom's Taxonomy to "rate" each objective, examination questions, and written assignments, a final classification for each was completed. The courses reviewed were specific to AT. With the basic AT coursework, $51 \%$ of the objectives focused on CT. The next tier of classes had $54 \%$ of the objectives and the top tier (senior level coursework) had $48 \%$. In looking at the examinations, only $13 \%$ of the basic AT level 
course questions focused on $\mathrm{CT}, 13 \%$ at the next tier, and $15 \%$ at the senior level. One notable finding was the gradual progression of $\mathrm{CT}$ in writing assignments with the AT curriculum. Overall the CT versus non-CT objectives was about equal, while the examination questions did not focus on CT. As Fuller states in his conclusions, and I concur, the focus of examinations at the basic level should stress knowledge and comprehension (recalling information); however, as the students progress into the upper tier classes, they should be tested on CT/higher order thinking skills. This would mean less multiple choice test questions and more essay type questions. However, I believe many curriculums focus on yielding high percentage results on the national examination, and, therefore, may teach to the test. Thus, $\mathrm{CT}$ is stressed in theory but not in practice.

In addition to this possible "teach to the test" phenomenon, there is one question in AT that still remains. Does DM in AT have any relationship with CT? First, the use of instructional approaches by CAAHEP curriculums, such as case studies, scenarios, and problem based learning techniques; appear to be strong predictors of success on pass rates of the NATABOC-WS (McLoda, T. A., Johnston, E. L., \& Hansen, A. J., 2005). However, during the same time this study was being conducted, Misasi, Davis and Shapiro (2005) were examining the correlation between CT and DM in AT. With an $N=51$, the researchers identified success on the NATABOC-WS and CT measured via the CCTST. They found no correlation between GPA, CT and success rate of the NATABOC-WS; however, they confirmed earlier research that there is a correlation between GPA and success rate on the NATABOC-WS (2005). Thus, because ATEP's continue to base educational outcomes on the idea of a CT-DM link that is based on the 
idea that CT skills increase within the ATEP curricula additional research in AT must identify if there is any relationship between CT and DM in AT.

\section{CT Evaluation}

How do we evaluate CT? Commonly used measurements include the WGCTA, the Cornell Critical Thinking Test (CCTT), Collegiate Assessment of Academic Proficiency (CAAP), and the Reflective Judgment Interview (RJI). All these assessments are valid and reliable and differ in the criteria for $\mathrm{CT}$ ability and can yield divergent results. According to Tsui's CT review (1998), the estimated correlation between the WGCTA and the RJI was found to be .27, and between the WGCTA and the CCTT was .54, and finally the RJI and the CCTT was found to be .27; this was following the correction for academic ability. These indicate weak correlations and the continued trend in the literature is that there was not an accurate tool to evaluate the ever controversial concept of CT, and so in the early 1990's, the California Critical Thinking Skills Test (CCTST) and the California Critical Thinking Disposition Inventory (CCTDI) were developed by Fancione, P. and Fancione N. and the first of its kind to derive its construct validity from the American Philosophical Association's Adelphi Report (Fancione, P., Fancione, N., \& Sanchez, 1994). However, no data has been found indicating any correlation with the older evaluations. Moreover, within most allied health literature, the WGCTA is used.

The challenge in choosing an evaluation tool for evaluating $\mathrm{CT}$ is defining and identifying CT. Once defined and identified, researchers can begin to study specifics of CT. Formal research in education on CT was largely impacted by the work of Dressel and Mayhew (1954). In a comprehensive, series of studies, many significant findings occurred. Testing thousands of college students, mostly freshman, from several 
institutions of higher education, and using varying methodologies, Dressel and Mayhew found that freshman CT gains are typically about half a standard deviation. This was true of pre and post testing at six of seven institutions, testing reasoning in sciences of 470 students. When looking at over 1700 social sciences students, again with pre and post testing (beginning and end of the semester) of CT, the same finding occurred. In another study of 1000 freshman's general CT skills, pre and post testing confirmed the original results. Thus, the literature is leading us to conclude that the greatest CT gains occur during the freshman year. However, this result appears consistent with general cognitive growth (Maiorana, 1992). Generally, research appears to indicate that more years of education yield higher CT scores. The Watson-Glaser Critical Thinking Appraisal Manual (WGCTA) (1980) shows MBA and third-year medical students scoring the highest on CT skills, while four-year college graduates score lower. However, only one study has examined college versus a non-college peer. Pascarella, (1989), sampled 47 participants, using pre and post testing with a semester equivalent duration, a college attending group was compared to a matched non-college-attending group. The results did show that basic maturation of CT occur independent of college attendance; however, the group attending college had a larger increase in CT. Due to the small participant numbers here, additional studies like this one need to occur. Therefore, can we assume college does improve CT skills or do CT skills occur due to maturation? If there is a minimal difference, can we use specific CT strategies to improve our students' CT skills? According to Jones and Ratcliff's review (1993), additional work by Pascarella found that 70 participants with one year of college show maturation to be minimal and college effects to be significant. 
Norris (1995) stated that CT at every level of schooling is lower than it should be. This is again confirmed by the WGCTA (Watson \& Glaser, 1980), which indicates that average test scores are at or below the $50^{\text {th }}$ percentile for every level of schooling. When looking at 37 college seniors, Keeley and Browne (1986) measured students' abilities to analyze an article via essay. After the critiques were completed, the researchers categorized the results. Many of the seniors did ask appropriate questions about sampling, statistics, and about the reasoning behind the article (about $40 \%$ asked one, $17 \%$ ask more then one). Yet, only one quarter identified a major implicit awareness of assumptions that are not tied to statistical discussions. Sixty-five percent of the seniors show indirect recognition of questionable assumptions. An unspecified number of seniors did not address the definitional issues of the article. Thus, they concluded that seniors pay closer attention to numbers than to words. All the students, regardless of ACT scores, did not ask certain critical thinking questions. The literature appears to indicate CT deficits in students at all levels, and even though CT has been a major goal of education (Maiorana, 1992), there does not appear to be any significant improvements.

\section{Decision-Making in Education}

While CT has become a major goal of education, all higher level thinking, including DM has begun to dominate the literature within higher education. Little research has been done on DM in the allied health profession, thus in order to understand $\mathrm{DM}$, one has to understand the conceptual idea of the cognitive domain and then understand how and why cognition contributes to DM. The education literature is rich with research comparing novice and expert teacher/practitioner. This educational 
literature looking at novice and expert practitioners closely parallels the idea of novice and expert clinicians. Thus, this section investigates DM in the field of education.

The ability of people to process all information in their environment is limited; and therefore, people must process this information step by step rather than simultaneously. This process incorporates short-term and long-term memory into the human information processing system to make judgments and decisions (Shavelson \& Stern, 1981).

Piaget's theory of cognitive development has two elements: stage dependent and stage independent. Focus on Piaget's work is usually on stage dependent. This focuses on the four stages of development: sensorimotor, preoperational, concrete operations, and formal operations. However, more recently the focus has shifted to the stage independent theory. This theory includes two processes: the adaptation of an individual to survive in a constantly changing environment and the need for organization or stability of the experiences of the past. This organized set of knowledge is called schemata. Piaget stated that individuals interpret and act according to schemata. Schemata are developed solely via environmental interaction (Reiber, 1991). The process of adaptation and organization create a conflict, which provides a springboard into learning. The goals of one are contrasted by the goals of the other. To balance the two processes is what Piaget termed equilibration. Assimilation and accommodation are the two parts of equilibration. Assimilation incorporates new information under what is already understood. Accommodation must build new ideas from old ideas when incoming information no longer fits the established schemata. Learning can only occur when the individual is in this state of chaos or disequilibrium (Reiber). 
This idea of schemata has been the focus of DM research within the field of education. Specifically, the schemata theory looks at behavioral and cognitive expertise (Dodds, 1994). With practice or practical experience, schemata develop over time. So when investigating expert/novice teaching differences, the differences are attributed to highly developed, richly detailed, interconnected cognitive knowledge (Berliner, 1987; Livingston \& Borko, 1989).

Berliner (1987) used a novice-to-expert model having five stages: a) novice: conscious concentration and forced use of rules; b) advanced beginner: mostly inflexible with some rule bending; c) competent practitioner who is able to draw on some experience but is still inflexible; d) proficient practitioner: use of holistic intuition; e) expert: intuitive, fluid, effortless action. Rovengo (1992) applied Berliner's novice-toexpert model on pre-service teachers in elementary physical education. Prior to student teaching, the pre-service teachers' knowledge of content was minimal and the students tended to oversimplify content. At the novice level, their schemata were literal, superficial, simple and unintegrated. Novices displayed hesitation in their performance and declarative knowledge, while experts were smooth and showed procedural knowledge. Champagne, Gunstone and Kloper (1985) determined novices and experts may not differ in information content, but novices lack schemata and the ability to retrieve it. This parallels the work of Borko \&Livingston (1989); who concluded that cognitive schema of novice teachers is less elaborate and interconnected, and that novice pedagogical reasoning skills are less developed.

Desforges (1995) challenged the idea that gaining experience helps teachers become more effective; experience does not typically build on what teachers learned in 
their teacher preparation programs, but does create highly contextualized beliefs. He argued that different stages in teacher expertise have not been shown to affect student learning or progress. "These are merely descriptors of difference with no evidence of how changes occur." Doyle (1986) concluded that expert teachers appear to show "functional blindness" to features within their practices that may affect student achievement and that they are more willing to "shut down" when facing an experience that varies from a generalized method rather than restructure their existing concepts. Unreflective experience is not necessarily helpful and in order for novice teachers to construct new warrants they must have a cognitive apprenticeship with reflection. Rovengo (1994) showed that teacher candidates in a new and difficult situation reverted back to relying on application tasks and did not learn from the situation. Reflectiveness appears to be one key as to how people learn from experiences, and without it, fail to learn from it. Another study done by Rovengo (1991), examined the pre-service physical education teacher and described the active, goal-oriented behavior and their restructuring of prior knowledge to form differentiated understandings of the teaching-learning experience.

Student teachers use three strategies to assist them with constraints they encounter in the schools: internalized adjustment (complies with constraints, believes they are the best, thus abandoning university teachings); strategic compliance (complies but retains reservations about these actions); and strategic redefinition (faces constraints but incorporates a new solution to the problem) (Lacey, 1987). This correlates with the current literature on negative socialization, where novice teachers revert back to their original warrants when confronted with instructional diversity, rather than continuing with the warrants implicated in the teacher education programs (Ennis \& Chen, 1993). 
Tillema (1995) concluded conceptual change and training needs to engage the preexisting warrants of professional teachers; otherwise the knowledge structure will remain unchallenged.

Additionally, individuals do not simply add information to their knowledge "banks," but revise existing concepts or formulate new concepts based on the existing concept, which is no longer adequate (Reiber, 1991). There is strong evidence in the educational research indicating that learners do not enter into learning situations as "blank slates." Instead, learners take their previous cognitive structures and warrants into the learning process and re-use, re-organize, modify, or discard such concepts as they apply to the current situation (Pearsall, 1992). Songer and Linn (1992) performed a study on 153 eighth grade students, finding that students' beliefs are important and can complement and/or hinder the development of knowledge.

Additionally, epistemic development is defined as learners' beliefs about knowledge and dispositions toward learning. Studies by Schommer (1990 \& et al, 1992) concluded that epistemic dimensions are better predictors than others for students' abilities to integrate information and avoid oversimplified conclusions. Researchers have concluded that students enter college with naïve epistemic dimensions and that professional growth in ill-structured domains is dependent on the development of assumptions about the complexity of knowledge.

Gagne (1977) concluded that epistemological attitudes are subject to learning and are malleable via training. With regard to specific training of epistemic processes, Spiro et al (1987) studied medical students and concluded that when confronted with multiple and diverse cases in a domain, the students show cognitive flexibility and enhanced 
problem-solving skills. Much of athletic training education, including clinical education has been based on medical and other allied health curriculums. With a curriculum that includes early and structured clinical experiences for students to apply didactic knowledge, ATEP's appear to be arranged in such a manner to improve student schemata and thus improve student DM. This idea of improving student's schemata is key to developing their skills as clinicians.

Academically generated knowledge was termed formal, abstract and conceptual, and experientially gained knowledge was classified as informal, specific and pragmatic (Leinhardt, Young \& Merriman, 1995). True integration of academic and experiential knowledge means examining the knowledge related to one location while using the ways of thinking associated with another location. Knowledge integration, according to Leinhardt et al. (1995), requires students to go into detail and interrelates abstract theories and develops abstract principles from the particulars of a real classroom. ATEP's are designed to allow students to take this academic, formal knowledge and transform it into specific, pragmatic experiential knowledge via didactic and clinical education settings.

\section{Decision-Making in Allied Health Professions}

AT has become a highly complex profession that exists within a rapidly changing health care environment. Thus, it is essential that certified athletic trainers be proficient in current knowledge and skills for providing safe and effective care. While athletic training continues to evolve, there are many adjustments being made for the education of athletic trainers. These changes in educational programs are focusing on competency-based education, which is the concept of repeatedly demonstrating competence of a skill in a variety of situations, forming the framework for a "learning over time" clinical education continuum (Konin, Amato, \& Brader, 
2002). These competencies should not be viewed as check lists of tasks, but rather a guide to acquiring clinical proficiency (Konin, et al). This idea facilitates a critical pathway from the classroom to the clinical environment. Therefore, the process must include the learning of psychomotor skills in conjunction with higher-level cognitive skills. To incorporate learning over time, the educator must learn to integrate these cognitive skills, problem-solving and decisionmaking skills, along with psychomotor skills across the curriculum.

As an example, Konin, et al (2002) discusses the learning of the Renne special test for iliotibial band syndrome begins in the classroom with foundational knowledge. This should be followed by a demonstration of the technique along with a discussion on when to use this special test. Students should then practice the technique, which would be followed by a written exam and a practical examination. The practical examination includes only the skill of performing the special test. However, having the opportunity to perform this technique on a model and also on an athlete that might have a positive test, would allow students to recognize when to apply this special test during an evaluation. This can be followed by a comprehensive evaluation or written simulation evaluation, where the student is given a scenario during their clinical rotation or during a computer simulation that forces the student to use the special test, when appropriate, during their evaluation of an athlete. Once the experience occurs, the learner is able to reflect and evaluate his/her actions. The learner can use this knowledge and accommodate or assimilate the new information with previous knowledge. This allows the learner to draw on that experience and apply it to the next scenario (Harrelson \& Leaver-Dunn, 2002). This example is prescriptive in nature and only suggests ideas for the ATEP educators to follow, and although Fuller (1997) found that programs are using some scenarios to test student's application of knowledge, it is 
unknown how many programs are using a written simulation examination similar to that used on the NATABOC certification examination.

In a study done by Schwartz, Donnelly, Nash, \&Young (1992), the purpose was to compare traditional instruction to Problem-Based Learning (PBL) in surgery clerkships. PBL stresses the acquisition of knowledge for the purpose of clinical problem solving. On factual knowledge the control group (traditional instruction) outperformed the experimental (PBL) group on quizzes; however, application was higher for the PBL group.

Payton (1985) suggested that physical therapy clinicians use clinical reasoning skills similar to that of physicians. In a descriptive study, he analyzed ten physical therapists (PT) ability to perform clinical problem solving and compared those with physician's problem solving. Using skilled therapists, observation and audiotaped sessions of initial evaluations were analyzed. Immediately following the evaluation of the patient, the therapist reviewed the audiotape. A key point of the evaluation technique included the therapist's ability to define a problem list and develop treatment plans as they collected additional data. This process is found to parallel that of physicians.

No studies like this have been replicated in athletic training; there is only a general assumption that ATC's are similar to PT's and other allied health clinicians in clinical reasoning skills.

\section{Relationship between CT and DM}

Reading the allied health literature, there is a consistent misuse of terminology. Are the terms "decision-making," "clinical judgment," "problem-solving," and "critical thinking" used interchangeably? Little literature within nursing and other allied health fields had examined the correlation between DM and CT. 
One of the first studies in nursing investigating the correlation between CT and DM also examined the differences between types of nursing programs (associate, baccalaureate, etc). Brooks and Sheppard (1990) compared the WGCTA and the Nursing Performance Simulation Instrument. The Pearson Correlation yielded an overall $r$ for all four programs, $r=0.249$, a weak but positive correlation. A second correlation study compared the WGCTA with the Jenkins' Clinical Decision-Making in Nursing Scale. This quasi-experimental study comparing 4 different groups (undergraduates from year one and year four, mature/experienced graduates, and mature/experienced practitioners), each group having varying levels of experience. Here they used the Spearman's rho correlation and only two of the four groups' scores were used. No correlation was found (Girot, 2000). In the final study using WGCTA, Hill (2002) examined respiratory therapists from ten programs and determined what the correlation was between the WGCTA and the Clinical Simulation Self-Assessment Examination. He found a positive but weak correlation $r=0.32, p<0.01$ between $\mathrm{CT}$ and DM skills.

No other studies to date have looked at the relationship between CT and DM skills in AT, nor have any of the allied health fields looked at this relationship with the CCTST. Allied health fields have looked at relationships of CT with PBL, clinical experiences and learning styles. Much more research needs to be done in this area.

\section{Summary and Conclusions}

$\mathrm{CT}$ and DM are complex and multifaceted. It is important to focus on both the cognitive and psychomotor domains and how CT occurs in both. Athletic training is a psychomotor profession, meaning that many of the skills needed to be effective are motor skills. Research in PE could also advance CT in AT. The lack of literature to date on CT 
within the psychomotor domain hinders the complete advancement of CT in AT. As AT educators, there must be a focus on the "synthesis" of these cognitive and psychomotor domains into a cohesive CT domain. Until the development of student cognition and CT in PE, much of the psychomotor CT development is unknown. CT in AT can only lead the way in developing $\mathrm{CT}$ in the psychomotor domain versus waiting for someone else to lead the way.

Basic knowledge and cognition are key components to understanding CT. Student cognition continues to evolve into a complex research area. Due to this complexity, many researchers choose to avoid it. Many find it difficult to evaluate and others regard both as barriers for additional studies. Due to these barriers, the research in this area is limited. In addition, when researchers focus on CT, there are many controversial issues. The largest, defining $\mathrm{CT}$, evaluating $\mathrm{CT}$, and identifying a teaching technique that promotes $\mathrm{CT}$ and $\mathrm{DM}$ are at the forefront of the controversy. It is almost easier to state what $\mathrm{CT}$ is not versus what it is. It is also easier to define $\mathrm{CT}$ by the cognitive skills needed and this includes problem solving and decision-making (i.e. the subscales). Ennis (1985) has provided a comprehensive definition that most researchers now use. Using standardized testing with multiple-choice items to test CT skills versus using essay items and using thinking aloud techniques add to the methodological confusion of evaluation. Researchers must remember that the standardized tests for evaluating CT have been proven valid and reliable (Watson \& Glaser, 1980). Finally, methodological confusion could be decreased with additional research focusing on what types of instruction promote $\mathrm{CT}$ in $\mathrm{AT}$. 
According to the Tsui review (1998) courses and programs that have been specifically designed to improve general CT (non-domain specific) have had mixed results. However, in comparison to courses taught in a traditional manner, greater gains in CT scores were found for courses with an instructional paradigm emphasizing problem solving or $\mathrm{CT}$, class participation and inquiry. The epistemological subject specificity suggests that different fields yield different reasoning; therefore, CT varies from field to field and that a full understanding of a field requires the ability to think critically in the field (Norris, 1989). AT curriculum focuses on increasing the application of the PBL, learning over time, and other similar teaching methods to $\mathrm{AT}$ in order to promote $\mathrm{CT}$ within the field; however, there is no evidence that ATEP evaluate DM skills outside of the clinical setting nor is it evaluated within the ATEP coursework.

In addition, the $\mathrm{CT}$ testing that is available is not subject specific but focuses on general CT. Research focusing on subject specific testing to evaluate CT levels within AT may also need to be addressed. This may include looking more at the CCTST versus the WGCTA; however, the general CT skills in AT must first be determined and a correlation determined for the WS-NATABOC prior to examining alternative ways of evaluating CT in AT. Since only one piece of research has been done in this area, and the correlation between $\mathrm{CT}$ and DM has not been determined, this study seems to be an appropriate way to continue this investigation. In addition, the WGCTA is a valid and reliable test for generalized learning. Many educators in the allied health profession understand the idea of lateral transference by Ausubel, Novak, and Hanesian (1978), that implies that students are able to transfer generalized learning (general CT) to other specific situations (AT DM) and build upon it. 
In addition, the field of athletic training must continue to do its own research to confirm critical thinking and clinical reasoning in the field instead of assuming skill transfer from the medical and or physical therapy fields. Athletic training literature is also lacking in regard to specific CT methods of instruction in AT and what would work best. It appears evident from the literature that whatever techniques are utilized, it will undoubtedly combine techniques from the field of physical education, allied health, and from the general education forum to increase the psychomotor and cognitive functioning of the clinical AT student. 


\section{CHAPTER THREE}

\section{METHODOLOGY}

\section{Introduction}

The purpose of this chapter is to present the methods used for this study. This chapter will discuss the participants, the research design, instrumentation, procedures, research hypothesis, and data analysis.

The purpose of this study was to determine if there is a relationship between critical thinking (CT) skills and decision-making (DM) skills in athletic training (AT) students. In addition, the study determined to what extent accredited athletic training education programs (ATEPs) use written simulations as a primary evaluation tool across the ATEP curriculum. Furthermore, this study examined differences in CT skills of AT students across the ATEP curriculum and if differences do occur, the study determined when these differences occur and to what magnitude they occur.

\section{Participants}

Two hundred and thirty nine college students participated in this study which was split into two portions, a correlation/descriptive design and a cross-sectional research design. For CT-DM correlation, 11 of the 41 college seniors majoring in athletic training from four CAAHEP (Commission on Accreditation of Allied Health Education Programs) ATEP's located in the state of West Virginia were eligible to sit for the National Athletic Trainers' Association Board of Certification Written Simulation (NATABOC-WS) in April 2005 and volunteered their results to the study. The four institutions included two private liberal arts colleges and two state supported research universities. Each ATEP program has been accredited for a minimum of 6 years, having 
a minimum of 18 students and a maximum of 37 students enrolled in the ATEP. Each program had a formal admission process that occurred either in the spring of the freshman year or in the fall of the sophomore year; however, due to students changing their major or transferring into an institution, some students applying into the ATEP were considered "freshman" ATEP students but by the institution, based on semester hours completed, were upperclassmen. However, for the purpose of this study only semester hours completed were investigated.

The second portion of the study sought to compare AT versus non-AT majors, with the target group consisting of college students, freshman through senior cohort levels or class rank, from the same four CAAHEP ATEP's within the state of West Virginia. Each cohort level varied in size, with an average of 8.4 students per cohort for each institution and thus combined totals for the ATEP group had an average of 34 students per cohort level and an average of 34 students from each school and from the four schools, a total of 135 students. In addition, the comparison group consisted of 104 non-ATEP college students, freshman through senior cohort level/class rank, enrolled in a non-specific general education or elective course at only three of the four West Virginia institutions. These courses were offered via elective/general education requirements. The researcher contacted the instructors for these courses in order to administer the WGCTA to these students. One general education sample was unable to be collected due to availability and scheduling issues. Again the cohort size varied with approximately 8.6 students in each institution's cohort and 35 students per institution with a total of 26 students per cohort level for the non-ATEP sample. The schools rank from Division I to Division II levels, private and public. The sample included 204 Caucasian, 14 African 
Americans, three Hispanic, 10 Oriental, and 1 Pacific Islander and seven individuals that did not report that information. The predominately Caucasian sample (204/239) included 122 males and 116 females ranging in age from 18 and over 23.

Participants were selected via convenience sampling. These students were currently enrolled in a CAAHEP AT program, recently admitted to the CAAHEP ATEP, currently applying into the CAAHEP AT program or were enrolled in a general education or elective course at the corresponding institutions. Due to issues of self-reporting, as well as the ATEP's admission requirements, some students classified themselves as freshman while having completed semester hours that placed them in another cohort. In addition, "true" ATEP first year students will not have begun any clinical rotations. Therefore, due to irregularities in self-reporting and inconsistent cohort status for ATEPs as a result of application processes, it was important to look at cohort by semester hour completed for both groups and clinical rotations completed for just the ATEP majors. Because sampling was not random, caution should be taken in generalizing results to other populations. However, due to the sample size, the diversity in the sample will likely reflect the diversity of any ATEP population as well as reflecting similar college campus populations at each of these specified institutions from which the sample was chosen.

Prior to data collection, approval from the Institutional Review Board for the Protection of Human Subjects was obtained (See Appendix A). A letter of information was distributed prior to students taking the Watson Glaser Critical Thinking Appraisal (WGCTA) explaining the participants' rights and risks in the study (See Appendix B). Participants consented by taking the appraisal. Participants received no compensation for 
participating; however, they were able to request their appraisal results. This may also assist the researcher in determining if students requesting scores perform better on their overall WGCTA score.

For the correlation portion of this study, 11 senior cohorts, ATEP student participants who agreed to participate in this phase of the study had their WS-NATABOC matched with their WGCTA by their birth date to ensure confidentiality of scores. For the descriptive portion of the study, the program directors for the four ATEP's were interviewed and provided descriptive information and syllabi regarding evaluation techniques for each ATEP course taught at their institution that specifically uses a written simulation evaluation format, as well as the program exit examination procedures for graduating seniors. In addition to the program information about evaluation techniques, specific to evaluating professional DM within their specified program, the program directors completed a demographic questionnaire (Appendix C) that aided the primary investigator with curriculum information regarding each institution and the required coursework of each curriculum. Finally, for the cross-sectional portion of the study, the 239 students who volunteered to take the WGCTA had their WGCTA scores noted by their cohort rank via semester hours completed.

\section{Research Design}

The study is a combined descriptive/correlation and cross-sectional design. For the correlational portion of the study, the researcher examined the relationship between CT skills and DM skills. All 11 participants were acquired via convenience sampling and were measured for CT skills via the WGCTA during their final semester of their senior year. In addition, these 11 participants were measured for DM skills via the WS- 
NATABOC examination in April of their senior year. Additionally, they voluntarily provided the results of their written simulation pass/fail of the NATABOC examination. These results were given to the corresponding program director. Once each participant provided verification of tests results, the program director forwarded this information to the primary investigator. Because scores were dichotomous for the WS-NATABOC and continuous for the WGCTA, a point-biserial correlation coefficient for the relationship between $\mathrm{CT}$ and DM in AT for all these senior students in each of these four CAAHEP programs was computed.

A correlation of CT and DM has only been done once within the AT literature and no significance were found between the WS-NATABOC and the California Critical Thinking Skills Test (CCTST). Therefore the current study continues to explore the relationship between $\mathrm{CT}$ and DM and is an exploratory study within AT and care should be taken in applying these results beyond those particular groups in West Virginia. Although the investigator is using instruments that are valid and reliable measures for CT and DM, other CT instruments could be used that may be a better indicator of CT skills within AT and have been used in other nursing studies. However, because the WGCTA has also been utilized within the nursing profession and other allied health fields to compare $\mathrm{CT}$ and $\mathrm{DM}$, this instrument appears to be adequate for use in $\mathrm{AT}$ for the measurement of CT skills. A major weakness to the study was that not all senior students volunteered their WS-NATABOC results, in addition, some senior students were not graduating in May and therefore, could not take the exam until a much later date, and thus there was a low sample size. Another weakness to the study was that participants failed to remember to forward their actual score of the WS-NATABOC to the 
investigator via their program director but instead relayed only pass/fail information, thus the correlation coefficient used had to be changed from the Pearson to the Point-Biserial and was calculated by hand using the computational formula for the Point-Biserial correlation coefficient (Heiman, 2003).

The descriptive portion of this study determined to what extent ATEPs use written simulation to evaluate their students enrolled in each of the required courses within the ATEP curriculum, as well as if the ATEP curriculum requires a senior exit exam and if so if it uses a written simulation as part of the comprehensive exit examination for the seniors enrolled in their programs. Thus, program directors provided only syllabi of courses that utilized a written simulation as a portion of the evaluation technique, as well as confirmation that the program exit examination procedures used written simulation evaluation techniques, and finally, a demographic questionnaire was completed (See Appendix C) to obtain a better understanding of each institutions' enrollment, the programs' student population, courses required, application procedures, and critical thinking assessment. This portion of the study may provide insight into each ATEPs evaluation techniques, specifically as to how the ATEP is preparing students for the certification examination. The demographic forms were emailed to program directors prior to the time ATEP students were given the WGCTA. The interview occurred when the researcher administered the WGCTA. Some syllabi were received via regular mail or via email. The investigator provided frequent reminders via email for program directors to return all requested information.

For the cross-sectional research design, the WGCTA was administered to two groups from all four-cohort groups (freshman, sophomore, junior, senior). The target 
group included the students enrolled in, or applying to the ATEP's from each of the four institutions and the comparison group consisted of four cohorts enrolled in a general education/elective course at each respective institution. During the last several weeks of the second semester, the WGCTA was administered to all cohorts. The researcher compared these subscales from the students enrolled in the ATEPs versus the non-ATEP students to identify differences in CT between groups. The researcher compared the individual subscales of the WGCTA from the cohorts across time for differences in CT across semester hours completed. Finally, the researcher determined at what point students had the greatest differences of CT within non-ATEP and within the ATEP curriculum. The dependent variables were the WGCTA subscales of inference, recognition of assumptions, deduction, interpretation and evaluation of arguments. The two independent variables are major (AT versus non-AT) and time (cohort level defined by semester hours completed). Cohort was identified as cohort via semester hours completed.

One strength to this type of study is that the researcher is examining not only the differences in cohorts, but comparing these differences between non-ATEP majors. This type of study has not been seen in the AT literature. However, some students chose not to participate in the study, enrollment was down at some institutions, and availability and scheduling affected the overall size of each group, thus decreasing the total $N$. Many students may not place a lot of emphasis or put much effort into taking the WGCTA. However, the researcher identified the number of students who requested their scores which may be an indicator of desire to perform well. Finally, this is a cross-sectional design with low cohort numbers, so caution must be taken in applying the results to other 
cohorts due to differences in cohorts and the amount of developmental change that may occur; however, the researcher believes that due to the overall number of participants, there was a diverse sample of both AT majors and non-AT majors to compare and contrast.

\section{Instrumentation}

A demographic questionnaire was used to acquire data on each ATEP senior cohort participant for the correlation aspect of the study. This questionnaire contained information on age, gender, cohort, race, high school and college grade point average (GPA), ACT/SAT scores, declared major and department, and clinical hours in AT , as well as when each senior ATEP student was sitting for the NATABOC-WS (See Appendix D). In addition, all other participants for the ATEP and non-ATEP participants provided the same demographic information but were not required to answer items that did not apply (See Appendix D). Although other studies have shown that age, gender, and race have no relationship to $\mathrm{CT}$, the researcher feels it is important data to collect to ensure that the sampling of convenience provides an accurate sample of the institution's population and that this same demographic data is also not related to CT within this population.

\section{Watson Glaser Critical Thinking Appraisal}

Many have argued the inability to truly test $\mathrm{CT}$ with a multiple-choice test. Many, such as Norris (1989), believe that additional testing via interviews or essay testing should be incorporated. Others have discussed the possibility of think aloud techniques along with one of the standardized CT tests (Watson \&Glaser, 1980). The WGCTA was developed to provide a sample of general CT abilities. The WGCTA may 
not be sufficiently precise to identify changes in $\mathrm{CT}$ due to instructional strategies at the college level (Jones \& Ratcliff, 1993). However, the WGCTA has been utilized throughout the allied health literature to identify changes in CT due to specific types of curriculum. Ultimately, the rationale for choosing an instrument is determined by the design of the study and the hypotheses to be studied. Again, looking at the CTA, one is testing general CT skills, not subject specific CT skills. The exercises include problems, statements, arguments, and interpretations of data similar to those encountered on a daily basis (Gadzella \& Baloglu, 2003; Watson \& Glaser, 1980). The participants would then choose the "best" answer for each.

The CTA is divided into five subtests:

1. Test one: Inference, which is discriminating among degrees of true and false facts of a given piece of data or information.

2. Test two: Recognition of Assumptions, which is recognizing stated and unstated assumptions in any given statement.

3. Test three: Deduction, which refers to the ability to determine if a given conclusion follows the given information.

4. Test four: Interpretation, the ability to examine the pros and cons of an argument and determine if the conclusions are justified.

5. Test five: Evaluation of Arguments, the ability to distinguish strengths and weaknesses of an argument on a particular problem (Watson \& Glaser, 1980).

The reliability of this test does indicate its effectiveness in testing general CT skills. However, if we are to follow Norris (1989), researchers can incorporate other types of CT instruments to improve the quality of their studies. Norris suggests the utilization of 
essay type questions, think aloud techniques to examine the thought process, and creating examinations that have relevance to the students would improve the validity of CT testing.

The WGCTA measures the ability of persons to think critically, the ability to reason analytically and logically. Because $\mathrm{CT}$ has become an important outcome for many academic disciplines, it is especially important for those training professionals in which careful, analytical thinking is an essential part of the job. While the WGCTA is intended to serve as a "power" test, not a speed test, most participants are able to complete any of the various forms in less than one hour. There are several forms or variations of the WGCTA; forms A, B, Y and Z. Form B was chosen for this study due to the ease of scoring and the decreased test time for the participant.

With the WGCTA being a pen to paper questionnaire; each 80 -item test assesses the five subscales which are grouped by 16 items per subscale and a final raw score or total CT score is calculated. Additionally, the raw score can be compared to means established by the WGCTA. The college norms are based on a weak systematic process and consequently may be less representative of their respective populations. Additionally, the norms are graduated, meaning that the percentile scores used for freshman cohort levels and upper division students vary in that if a student has a raw score as a freshman of 59/80, their percentile based on the norms is at $70^{\text {th }}$ percentile; however, in order to have a $70^{\text {th }}$ percentile as an upper classman, the student must now score $64 / 80$.

The test can be scored by hand; multiple responses to the same item will be crossed out with a colored line that will show through the key. To score Form A or B by hand, the researcher will place the correct scoring sheet over the answer sheet so that the 
two corresponding blue dots in the lower right-hand corner overlap. The researcher will count the number of correctly marked spaces and record the total individual subscale scores and the raw score on the answer sheet. A third party, not involved with the study, will grade the tests in the same fashion to determine inter-rater reliability. Caution must be taken when using the subscales individually due to the relatively small number of items within each subscale and the fact that the sub-scores may lack sufficient reliability when used separately. However, due to the fact that each subscale yields an equivalent score and because the subscales are similar yet different in nature, the researcher will investigate these subscales for any relationship.

Reliability. The reliability of the WGCTA was examined in a variety of ways: internal consistency, stability of test scores over time, and the correlation between scores on alternate forms. Internal consistency was measured using the split half correlation coefficient. The coefficients range form .69 to .85 (Watson \& Glaser, 1980). The total CT score has had the highest internal consistency at .86, while the individual sub-scores range from .57 to .83 (Gadzella \& Baloglu, 2003). Therefore, the total score is statistically more reliable then each of the individual subscales. The stability of responses over time was examined using a group of college students at which the WGCTA was given at two different times. The correlation between the two times was calculated at .73 . Alternate form reliability was examined by comparing the various Forms A and B tests, and was calculated to be .75 (Gadzella \& Baloglu, 2003, Watson \& Glaser, 1980).

Validity. The validity evidence of the WGCTA has been drawn from various studies using all four forms in various settings. This is due to the characteristics of the 
test to and its ability to be applied in alternate settings with various subjects. The extent to which the WGCTA measures a sample of the specified objectives of various instructional programs and instructional settings is an indication of its content and construct validity (Watson \& Glaser, 1980). Gadzella and Baloglu (2003) calculated the validity coefficients, for those students majoring in education and enrolled in an educational psychology course, by computing correlation coefficients among total and subscale scores with course grades. The highest correlation was between total score and course grades with an $r=.42$.

Written Simulation portion of the National Athletic Trainers' Association Board of Certification Examination (WS-NATABOC)

The NATABOC has developed an examination that make up the certification component for athletic trainers. Comprised of three parts: a written, 150 multiple-choice item examination, a practical/oral examination of ten problems or tasks, and a written simulation test of eight multi-part scenarios, the test is used to determine basic knowledge of entry-level athletic trainers. Specifically, the WS-NATABOC assesses professional judgment and decision-making. To evaluate the ability of the examinee to assess a situation and make appropriate decisions, candidates are given written scenarios similar to those they would encounter in an actual clinical or athletic setting. They must then choose the most appropriate response(s) or action(s) from a list of several options. Each response is categorized as clearly indicated, indicated, neutral, contraindicated and clearly contraindicated and weighed according to the importance of the portion of the scenario in which it is located. Therefore, when choosing a response, students may earn a positive $(+)$, zero $(0)$, or negative $(-)$ score. Scores are then calculated in accordance with 
the scoring formula and reported on a scale from 200 to 800 (Castle, 1999) and students are notified of their score and a pass/fail status.

Reliability. One measure of reliability used to evaluate the WS-NATABOC is the Kuder-Richardson Formula 20 (KR-20), which measures internal consistency. Since 1999 to present, the KR-20 for the written simulation has ranged from .88 to .95 . The standard error of measurement (SEM) or the range within which the subjects' true scores lay, ranged from 20.46 to 33.06 from 1999 to 2001, but in 2002 the SEM dropped to 7.7, a significantly lower SEM then in years past (Annual Report, 1999, 2000, 2001, 2002). The 2002 Annual report does not provide reasons for this significant decrease.

Validity. The written simulation committee of the NATABOC writes reviews and validates new scenarios each year. The current test bank of simulation problems includes 30 scenarios. Each year, the NATABOC administers two versions of the simulation test. The ability of the examination to accurately assess entry-level ATs is based largely on content validity. Each scenario is matched to the role delineation. The role delineation defines the performance domains of athletic training and further breaks down these domains into tasks, skills, and knowledge areas. All the items for the examination are written by practicing athletic trainers, athletic training educators, and by some allied health professionals (i. e. physical therapists, physicians) and are based on this role delineation. Each writer is trained in writing, reviewing, editing and validating questions. Each item is categorized by content, assigned a cognitive level of Bloom's taxonomy, and validated. In addition, each item must have two verifiable references. Once in the test bank, the problems are randomly selected and reviewed to ensure no item has been duplicated. Following each certification year, each item is reviewed and changes made 
as appropriately determined. If according to the statistics, an item was inappropriate or questionable, then it is revised or eliminated (Castle, 1999).

\section{Procedures}

Written support (email confirmation) from the ATEP program directors of all four CAAHEP schools in West Virginia was obtained for participation of ATEPs and corresponding institutions. Authorization was also granted from the instructor of each general education course, which was used as a control, from each institution. Approval was sought from the Institutional Review Board for the protection of human subjects. Consent was also acquired from the publishers of the WGCTA for use in a research project and copyright materials were obtained via the purchasing of the required materials.

Following these approvals, students were informed of the current study and encouraged to participate; however, individuals were also informed that there was no penalty for not participating in the study. During the last several weeks of the second semester, freshman, sophomore, junior and senior AT majors and their corresponding non-AT major cohorts enrolled in general education courses (i. e. first aid and safety, a PE activity course, etc) at each respective college was contacted and informed of the study and given the option to participate. Those students who participated in the study obtained a letter of information and completed a demographic questionnaire, and then the WGCTA was administered. Students were given 50 minutes to take the appraisal. Following the completion of the CT appraisal, all participants, with the exception of the senior AT majors, had completed their participation in the study. The senior AT majors who volunteered to provide their WS-NATABOC results from the April test date and 
upon receipt of these results reported their test results to their program director, which were forwarded to the researcher via email. To ensure the researcher was able to pair the scores with the WGCTA, the tests scores were obtained using date of birth instead of names to ensure confidentiality. In addition to the test results, the program director forwarded all syllabi and program exit procedures utilizing written simulation evaluation techniques. This was done to verify the use of written simulation evaluations within their ATEP curriculum. Finally, following completion of the program director's demographic questionnaire, the program director was interviewed by the researcher and provided all requested information to the investigator via email, postal mail and/or hand delivery.

The demographic questionnaire for ATEP directors (Appendix C) provided specific information regarding the ATEP, such as type of institution, size of institution, size of ATEP, ATEP cohort size, number of major required courses, and application processes used for each. This information allowed the investigator the ability to compare programs and identify similarities and differences. The demographic provided types of evaluations used for courses as well as identifying which programs require a senior exit examination. The investigator identified if any of the institutions utilize a written simulation examination (and what type) to evaluate AT students at any point within their curriculum. In addition, the demographic recognized alternative ways in which ATEP's evaluate students' CT and DM across the ATEP curriculum.

\section{Research Hypothesis}

Based on the review of the literature regarding $\mathrm{CT}$ skills and the relationship to DM skills, the lack of literature within AT regarding this relationship, and the continued low pass/fail rate of the NATABOC examination, the following hypotheses were made: 
1. There is a positive correlation between CT skills and DM skills.

2. ATEPs do not use written simulation evaluation techniques across the curriculum.

3. AT majors will have higher CT skills than non-ATEP majors.

4. The greatest differences for non-AT majors will be in the freshman year; however, the greatest differences for AT majors will occur after their admission into the ATEP.

\section{Data Analysis}

Statistics were employed via SPSS statistical package, $11^{\text {th }}$ edition (SPSS, Inc, 1998). The demographic information provided allowed the investigator to identify if students are ATEP or non-ATEP students and in which cohort they belong. In addition, some of the demographic information allowed for specific sample characteristics that allowed the investigator to compare average age, gender and race to the WGCTA. This assisted the investigator in identifying if the convenience sample identified if there is a relationship between age, gender and race to the WGCTA.

In order to test the first hypothesis, a Point-Biserial Correlation Coefficient was computed by hand since SPSS does not run the Point-Biserial Correlation. Having SPSS calculate the means and standard deviation for each group (passing versus failing) and using the computational formula provided by Heiman (2003) the researcher was able to determine if any relationship existed between CT skills and DM skills. Because the researcher was trying to determine the degree and direction of the linear relationship between these two variables (CT and $\mathrm{DM})$ and due to the data being continuous variable and a dichotomous variable, the Point-Biserial was chosen over the Pearson and the Spearman. In addition, the investigator wanted the ability to compare and contrast the 
results of this study with others of its kind that have been completed in other allied health fields (e. g. nursing) thus, using an independent t-test would not allow for a comparison of coefficient relationships.

To test the second hypothesis, via the demographic questionnaire and personal interview, the investigator identified if any ATEPs use written simulations at any point within the curriculum. If ATEP's utilize a written simulation, the investigator calculated what percentage of the courses within the ATEP's curriculum use written simulation evaluation procedures. Moreover, the investigator determined what percentages of ATEPs have senior exit examinations and what percentage of these programs use written simulations during these procedures.

The remaining two hypotheses were analyzed using a 2X4 MANOVA with all five subscales from the WGCTA as the five dependent variables and where factor A is AT versus non-AT majors and Factor B is cohort via semester hours. This alternative classification of cohort via semester hours completed is grouped as follows: freshman $=0$ $30 \mathrm{hrs}$, sophomore $=31-60 \mathrm{hrs}$, junior $=61-90$ hours, and senior $=90+$ hours. A Bonferroni (less conservative) and a Scheffe (most conservative) post-hoc pair wise comparison determined where (in which cohort) the greatest differences occur. The MANOVA and post hoc testing was calculated to the .05 Alpha levels. To control for type-one error, the MANOVA was used for the multiple dependent variables of the subscales over the independent t-tests or multiple ANOVA's and the post-hoc test were used because of the range of their conservative levels and should, therefore, decrease the risk of type-one error. Finally, the size of the sample should control for type-two error. However, the 
researcher attempted to ensure each cohort to have sufficient numbers to rule out typetwo error as well. 


\section{CHAPTER FOUR \\ RESULTS AND DISCUSSIONS}

\section{Introduction}

The purpose of this chapter is to present results and discuss findings in light of the hypotheses stated in chapter three. To accomplish this purpose, this chapter is organized to include a demographic analysis, a re-statement of the hypotheses, results and discussion for each hypothesis tested and a conclusion.

\section{Demographic results}

A univariate analysis of variance was used to identify if any demographic information was significantly correlated with the Watson Glaser Critical Thinking Appraisal (WGCTA) total raw score. The analysis indicated no significance with the demographic data. Unfortunately, additional academic demographic information (high school GPA, college GPA, SAT and/or ACT scores) was collected; but due to inconsistencies in selfreporting, participants reporting they were unsure of the information or participants leaving information blank, there was not sufficient data to be analyzed. In addition to the lack of significance found in both main effects and sequential interactions for the demographic data, the effect size (noted by Eta Squared or ES) was low, which parallels most social research that yields an effect size of low to moderate (Grimm \& Yarnold, 1995). 
TABLE 1: Demographic analysis (Interactions not included and not significant)

\begin{tabular}{|l|l|l|l|l|}
\hline Demographics & $\begin{array}{l}\text { DF (Btw grp, W/In } \\
\text { grp) }\end{array}$ & F value & P value (sig.) & $\begin{array}{l}\text { Eta squared (effect } \\
\text { size) }\end{array}$ \\
\hline Gender & 2,206 & .916 & .402 & .009 \\
\hline Race & 5,206 & .535 & .75 & .013 \\
\hline Age & 5,206 & 1.519 & .185 & .036 \\
\hline
\end{tabular}

\section{Demographic Discussion}

Based on the demographic information collected and the data analysis, gender, race and age have no relationship to or impact on critical thinking. This supports the findings of previous literature looking at gender and race where no significant findings indicated that these factors affect critical thinking (Scott, Market \& Dunn, 1998). Additionally, age was not a significant factor; however, having a higher $\mathrm{F}$ value then the others, it appears that these cross-sectional findings may not be as accurate as the longitudinal findings reported by Vaughn-Worbel, O'Sullivan, and Smith (1997) that indicated upon entry to nursing programs, older students and students with previous degrees, have higher CT. Additionally, other CT tests have yielded similar results of demographic data. The California Critical Thinking Skills Test and the California Critical Thinking Disposition Inventory have been found to have no significant relationship with age, gender, or race (Fancione, Fancione, \& Sanchez, 1994; LeaverDunn, Harrelson, Martin, \& Wyatt, 2002). Additionally, with the effect size measuring a low magnitude of the differences in the means, the results of this study appear to indicate that age, race and gender do not relate to CT when measured by the WGCTA. 


\section{Hypotheses}

To answer the study's research questions, the hypotheses as stated in Chapter Three were subjected to data analysis using SPSS 11.0 software. Prior to analysis, the researcher correlated each subscale of the WGCTA to show how much overlap there was between the dimensions of critical thinking. Each subscale yielded a low Pearson Correlation Coefficient (ranging from .07-.485) indicating that each of the subscales was un-related and demonstrates that each of these subscales assesses different components of CT. Thus the researcher was able to use the individual subscales instead of the raw total score for data analysis. The results of the data analysis will follow.

\section{Hypothesis One Results}

To test the first research hypothesis, "there is a positive correlation between CT and DM in AT," only the senior ATEP students who sat for the National Athletic Trainers' Association Board of Certification Written Simulation (NATABOC-WS) Examination were subjected to the Point-Biserial Correlation Coefficient. An unexpected threat to internal validity occurred as the researcher realized that not all ATEP seniors would be eligible for the April and June test dates. Another methodological issue arose in that students were to report their actual score of the WS but failed to do so and only reported their pass/fail status. This may have occurred because students performed poorly on the WS overall or because they were only focused on the pass/fail status and did not look at the actual score. Of the 41 seniors, 11 of 13 seniors, eligible for the April examination date volunteered their NATABOC-WS score and reported the pass/fail status to their program director. Additionally, six seniors will sit for the NATABOC on the June test date, two in August, while the remainder will sit in November or due to 
academic requirements, will not sit until the following year. This researcher will continue to collect data until November. Based on the analysis of the 11 seniors who have reported scores, a correlation coefficient was run using their WS pass/fail results with their WGCTA raw score. Because SPSS does not run a Point-Biserial analysis, this was calculated in part by hand, using SPSS to calculate the mean for each group (pass/fail) and the standard deviation for all 11 students. These numbers are reported in Table 2. A Point Biserial correlation for the data revealed that the amount of CT in AT (measured by the WGCTA) and the DM abilities (measured by the NATABOC-WS) were not significant, $r=+.1226, n=11, p=<.05$. Therefore, it appears that there is no relationship between $\mathrm{CT}$ and DM in AT, moreover, the hypothesis one was not accepted. However, due to the low $N$, caution must be used in generalizing these results. Additionally, when the primary investigator evaluated each group (the group passing versus the group failing the WS), the means for each group indicated percentile scores at only the $20^{\text {th }}$ and $15^{\text {th }}$ percentile, respectively, thus indicating that neither group performed well on the WGCTA. Again caution should be taken in generalizing these results due to the low $N$ and because there is no mean average established for this group and so the researcher based these percentiles on the average means for college students. That being said, additional research in this area should be done to establish ATEP students' abilities to think critically.

TABLE 2: Point Biserial Data

\begin{tabular}{|l|l|l|}
\hline Mean (passing) & Mean (failing) & Standard deviation (all) \\
\hline 51.6 & 50 & 6.498 \\
\hline
\end{tabular}




\section{Hypothesis Two Results}

To test the second hypothesis, "ATEP curriculums do not use a written simulation as an evaluation tool within their curriculums," the researcher had each program director report demographic data on each ATEP and each was interviewed for clarity. Three of four $(75 \%)$ institutions institute a senior exit examination and all three $(100 \%)$ of these programs utilize a computer-based written simulation as a portion of the evaluation process for this exit examination. Additionally, while all four (100\%) institutions reported utilizing instructional methods that promote $\mathrm{CT}$, only three used comprehensive oral examinations as an evaluation tool during clinical rotations. During these comprehensive oral examinations, a scenario is given to the students and they are evaluated on their ability to evaluate an injury. According to each institution, the evaluation is done by one Approved Clinical Instructor (ACI) or by the Coordinator of Clinical Education. Only the liberal arts institutions (two) utilize written simulation evaluation procedures throughout the didactic portion of the curriculum. Both these colleges begin using the written simulation evaluation in the first semester the students enter the ATEP curricula and continue its use throughout the students' career; however, even within these two institutions, this equates to using a written simulation in only $11 \%$ of the required courses. Therefore a written simulation evaluation, although used, is not utilized across the ATEP curricula, and hypothesis two was accepted. Again, caution should be taken in generalizing these results as this study only looked at four institutions in the state of West Virginia. Future studies should survey all ATEP accredited programs to validate these results and to investigate if this usage affects pass/fail on the NATABOC-WS. 


\section{Hypothesis Three and Four Results}

To test the third hypothesis, "do ATEP students have higher critical thinking skills then the non-ATEP students enrolled in the college setting," the entire sample was subjected to a $2 \mathrm{X} 4$ multivariate analysis (MANOVA). The dependent variables investigated were the subscales of the WGCTA: 1) inference, 2) recognition of assumptions (recognition), 3) deduction, 4) interpretation, and 5) evaluation of arguments (evaluation). The first fixed variable identified major versus non-AT majors; while the second fixed variable was cohort level. The classification of cohort was determined by semester hours completed. Finally the interaction of the two main effects was analyzed.

The means, standard deviations and ranges are presented in Table 3. The $2 \mathrm{X} 4$ MANOVA analysis showed a significant main effect for the major factor, $\mathrm{F}(1,231)=$ $6.006, p<.001$; Additionally, the effect size for the major factor was small, $\mathrm{ES}=.117$ (See Table 4). Further investigation of the majors' variable for repeated ANOVA analysis showed that inference, deduction, interpretation, and evaluation were all significant; however, recognition was not significant (Refer to Table 5). Additioanlly, effect size for these subscales ranged from low to moderate. Due to the fact that there were fewer than three groups, additional post hoc analysis was not done on factor A. Caution should be used in accepting these main effect results until the interaction effect is analyzed. However, based on this main effect, regarding hypothesis three, ATEP majors do have higher critical thinking skills compared to non-ATEP college students and thus hypothesis three was accepted. An unexpected threat to internal validity is that the researcher was unable to obtain a non-ATEP sample from one of the schools and this 
may have affected the results. Therefore, caution should be taken in generalizing these results until further studies can validate these findings.

TABLE 3: WGCTA Subscale Norms and Descriptives for major *semester hours interaction:

\begin{tabular}{|c|c|c|c|c|c|c|}
\hline $\mathrm{DV}$ & Majors & Sem Hrs & Mean & Std. Dev. & Range (low) & $\begin{array}{l}\text { Range } \\
\text { (high) }\end{array}$ \\
\hline \multirow[t]{8}{*}{ Inference } & ATEP & Freshmen & 7.4 & 2.3 & 6.7 & 8.1 \\
\hline & & Sophomore & 8.2 & 2.2 & 7.3 & 9.2 \\
\hline & & Junior & 6.9 & 2.1 & 5.9 & 7.8 \\
\hline & & Senior & 7.6 & 1.7 & 6.9 & 8.4 \\
\hline & Non-ATEP & Freshmen & 6.3 & 3.0 & 5.3 & 7.3 \\
\hline & & Sophomore & 5.9 & 2.6 & 5.1 & 6.7 \\
\hline & & Junior & 6.4 & 2.6 & 5.3 & 7.4 \\
\hline & & Senior & 7.5 & 3.2 & 6.4 & 8.4 \\
\hline \multirow[t]{8}{*}{ Recognition } & ATEP & Freshmen & 9.4 & 3.3 & 8.4 & 10.4 \\
\hline & & Sophomore & 9.7 & 3.6 & 8.4 & 11.0 \\
\hline & & Junior & 10.3 & 3.3 & 9 & 11.6 \\
\hline & & Senior & 10.4 & 3.5 & 9.4 & 11.4 \\
\hline & Non-ATEP & Freshmen & 8.0 & 3.1 & 6.7 & 9.4 \\
\hline & & Sophomore & 9.2 & 3.2 & 8.1 & 10.3 \\
\hline & & Junior & 8.9 & 3.8 & 7.4 & 10.3 \\
\hline & & Senior & 11.1 & 2.8 & 9.8 & 12.5 \\
\hline \multirow[t]{2}{*}{ Deduction } & ATEP & Freshmen & 8.9 & 2.7 & 8.1 & 9.6 \\
\hline & & Sophomore & 10.5 & 2.4 & 9.6 & 11.4 \\
\hline
\end{tabular}




\begin{tabular}{|c|c|c|c|c|c|c|}
\hline & & Junior & 9.5 & 2.5 & 8.6 & 10.5 \\
\hline & & Senior & 9.5 & 1.9 & 8.7 & 10.2 \\
\hline & Non-ATEP & Freshmen & 9.3 & 2.6 & 8.3 & 10.2 \\
\hline & & Sophomore & 8.6 & 2.1 & 7.8 & 9.4 \\
\hline & & Junior & 7.7 & 2.4 & 6.7 & 8.7 \\
\hline & & Senior & 9.4 & 2.4 & 8.4 & 10.3 \\
\hline \multirow[t]{8}{*}{ Interpretation } & ATEP & Freshmen & 10.4 & 2.5 & 9.7 & 11.2 \\
\hline & & Sophomore & 12 & 1.7 & 10.9 & 13.0 \\
\hline & & Junior & 10.9 & 2.4 & 9.8 & 12.0 \\
\hline & & Senior & 11.5 & 2.5 & 10.7 & 12.3 \\
\hline & Non-ATEP & Freshmen & 9.1 & 3.0 & 8.1 & 10.2 \\
\hline & & Sophomore & 9.1 & 2.8 & 8.3 & 10.0 \\
\hline & & Junior & 9.1 & 3.2 & 8.0 & 10.2 \\
\hline & & Senior & 10.6 & 2.9 & 9.5 & 11.7 \\
\hline \multirow[t]{8}{*}{ Evaluation } & ATEP & Freshmen & 11 & 3.0 & 10.2 & 11.7 \\
\hline & & Sophomore & 11.1 & 1.9 & 10.2 & 12.0 \\
\hline & & Junior & 11.3 & 1.9 & 10.4 & 12.3 \\
\hline & & Senior & 10.7 & 2.2 & 10 & 11.5 \\
\hline & Non-ATEP & Freshmen & 9.3 & 2.2 & 8.3 & 10.3 \\
\hline & & Sophomore & 9.6 & 2.4 & 8.8 & 10.4 \\
\hline & & Junior & 9.8 & 2.6 & 8.8 & 10.9 \\
\hline & & Senior & 10.3 & 1.9 & 9.4 & 11.3 \\
\hline
\end{tabular}


GRAPH 1: Raw scores for ATEP vs. Non-ATEP students across cohort levels

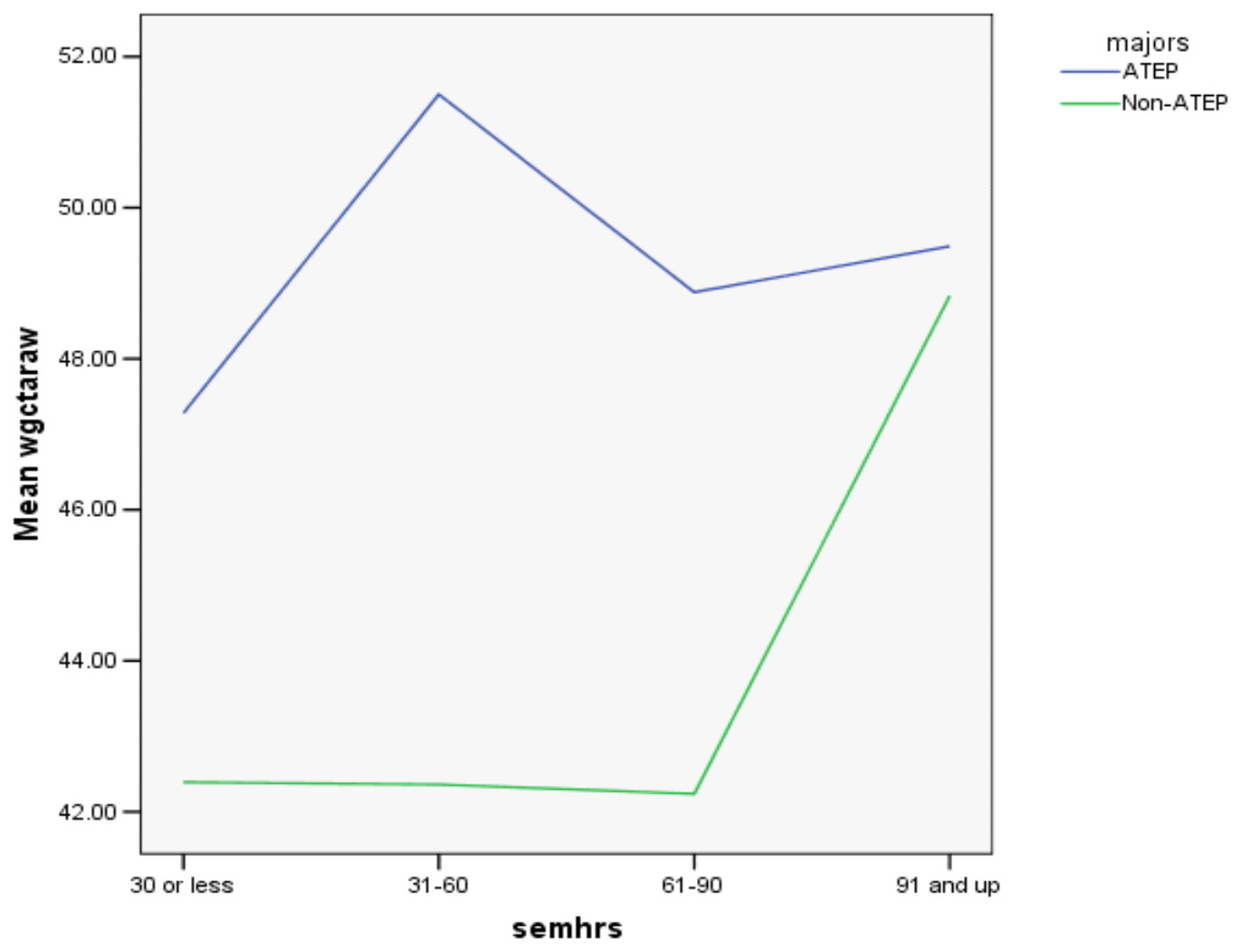

TABLE 4: 2X4 MANOVA Main effects and Interaction

\begin{tabular}{|l|l|l|l|l|l|}
\hline & DF & Wilk's Lambda & F value & Sig. & $\begin{array}{l}\text { ES (Eta } \\
\text { Squared) }\end{array}$ \\
\hline MAJORS & 1 & .833 & 6.006 & $<.001$ & .117 \\
\hline SEM. HRS & 3 & .903 & 1.581 & .074 & .034 \\
\hline Maj * Sem Hrs & 3 & .906 & 1.522 & .092 & .032 \\
\hline Error & 231 & & & & \\
\hline
\end{tabular}


TABLE 5: Univariate Analysis- Fixed variable- Major

\begin{tabular}{|l|l|l|l|l|}
\hline Subscales & $\begin{array}{l}\text { DF (Btw group, } \\
\text { W/in group) }\end{array}$ & F Value & Sig. & ES \\
\hline Inference & 1,231 & 9.99 & .002 & .04 \\
\hline Recognition & 1,231 & 2.23 & .137 & .01 \\
\hline Deduction & 1,231 & 7.09 & .008 & .02 \\
\hline Interpretation & 1,231 & 23.53 & $<.001$ & .09 \\
\hline Evaluation & 1,231 & 16.18 & $<.001$ & .07 \\
\hline
\end{tabular}

For the final research question, identifying at what cohort level the greatest differences occurred for each group, the entire sample subjected to the 2X4 MANOVA analysis, identified the significance of the interaction effect. The researcher looked at the majors factor and the cohort factor (semester hours completed) interaction. As stated in the methods, freshman were those with 30 or less semester hours completed, sophomores completed 31-60, juniors completed 61-90 and seniors had 91 or more semester hours completed. The 2X4 MANOVA revealed no significant main effect for the cohort factor, $F(3,231)=1.581, p=.07$; and no significant interaction between the major and cohort factors, $F(3,231)=1.522, p=.09$. Thus with the fixed variable semester hours completed not being significant at the $\mathrm{p}=.05$ level, nor the interaction between cohort and major, further post hoc analysis was not performed on this data. Furthermore the univariate analysis on the dependent variables indicated that all of the subscales did not violate the assumption of homogeneity, with the exception of the inference subscale (Levene's Test of Equality of Error Variances $=.015$ ). Thus the two populations from which the sample was selected had equal variances in all but one subscale. 
Although there was no significance found for the interaction of semester hours completed and majors, the mean differences were identified for each group to document where the greatest differences lie (See Table 3). Although the ATEP group scored consistently higher in each subscale across cohort levels, with the exception of deduction at the senior cohort level and deduction at the freshman level, the overall mean scores for both groups (See graph 1) indicated low percentile scores for each group overall (ATEP $15^{\text {th }}-25^{\text {th }}$ percentile and Non-ATEP $5^{\text {th }}-15^{\text {th }}$ percentile) (WGCTA Manual, 1980). For the subscale inference, mean differences for the ATEP group was greatest between the freshman and sophomore year and between the junior and senior year, while the nonATEP group mean difference was greatest between the junior and senior year. For the subscale recognition, mean differences for the ATEP group were greatest sophomore to junior year, while the non-ATEP mean differences were greatest between the junior and senior year. For the subscale deduction, mean differences were greatest for the ATEP group between freshman and sophomore year, while non-ATEP group mean differences were greatest from junior to senior year. Interpretation mean differences were greatest for ATEP freshman to sophomore year and non-ATEP differences occurred again at the junior to senior level. Finally, the evaluation subscale had the greatest differences (all be it small) for the ATEP group again in the freshman to sophomore year and the non-ATEP had similar small gains but again the greatest differences were between the junior and senior year. Thus hypothesis four was not accepted. Although the cohort level $n$ was lower then the researcher had hoped, the requirements for running a MANOVA were met and therefore, that threat to internal validity was controlled for. However, care should be 
used in generalizing these results as this was a cross-sectional study and therefore shows a picture in time versus changes across time.

\section{Hypothesis One Discussion}

The problem addressed in this study is a challenge faced by ATEP educators of improving students' DM skills in order to prepare these future clinicians for the advanced ATC roles they will hold in the future. Based on the idea that there is a positive correlation between $\mathrm{CT}$ and $\mathrm{DM}$, the development of $\mathrm{CT}$ has been a proposed method for increasing and improving DM.

Moreover, understanding that AT has been recognized as an allied health profession since the early 1990's, much of the literature on which ATEP has been founded comes from other allied health fields. Many times the literature will interchange CT, DM and problem solving as words basically having the same meaning; however, this might have created a false idea that these processes have a positive correlation.

Additionally, much of the educational rationale is based on the idea of promoting CT and thus improving clinical DM. While there have been very few studies having a strong support for the correlation between CT and DM, educators continue to focus on the CTDM link as if it has been firmly established in the literature. Ironically, previous studies that have been completed have found only moderate to weak correlations between CT and DM. Moreover, AT has only looked at this relationship one other time and yielded no significant relationship between $\mathrm{CT}$ and DM. But with an $N=51$, AT must continue to investigate this relationship and determine if in fact any relationship between these two factors exists. 
Statistically, for any correlation, the higher the $N$, the increased power of the study and the increased chance for a stronger correlation and may have been a threat to the internal validity of the study. The four studies that parallel this study all had variable $\mathrm{N}$ values. The first two were in nursing and had an $N=200$, which had a Pearson $\mathrm{r}=.249$ (Brooks \& Sheppard); and an $N=82$, that had a Spearman $\mathrm{r}=-.014$ (Girot, 2000). Within the field of respiratory therapy, one study had an $N=143$, which had a significant $\mathrm{r}=.32$ with 110 of 143 participants taking one DM test while the other 33 students took an alternate form of the DM test and had a non significant $r=.21$ (Hill, 2002). Finally, within AT, a study had 51 participants and yielded a non-significant $\mathrm{r}=-.23$ (Misasi, Davis, \& Shapiro, 2005).

Although this researcher hypothesized a positive correlation would occur between these variables, based on the literature in other allied health fields, the researcher also assumed this study would yield only a weak to moderate correlation. While this study hoped for a larger $N$, the results of this study did parallel the results in AT found by Misasi, Davis and Shapiro (2005). Furthermore, the literature has yet to establish a strong correlation within the allied health field, which may indicate the need for a much more comprehensive analysis of the DM-CT link.

Of major concern is that CT scores for both ATEP seniors (passing and failing) were low overall when looking at mean averages/percentiles based on that of college students. This may indicate that AT students do not have strong critical thinking abilities. This may be in fact a reason why NATABOC-WS pass rates are low. Future studies must be done to evaluate CT skills of ATEP students. Additionally, it should be established if AT students have strong CT abilities to begin with. With ATEP students 
having a predisposition to think critically (Lever-Dunn et al, 2002), it may be assumed that they do in fact think critically. However, with the low percentile scores yielded by the pass and fail groups, the question of the level of CT skills enters the forefront. Again caution should be taken in generalizing these results due to the low $N$ and because there is no mean average established for this group and so the researcher based these percentiles on the average means for college students.

\section{Hypothesis Two Discussion}

With the NATABOC currently using a pen-to-paper written simulation and moving toward a computer-based written simulation to evaluate DM for certification, it appears important that ATEP's utilize simulations during a student's educational experience. With a low pass rate of those taking the written simulation test for the first time (Annual Reports1999-2004), programs are continuously trying to improve their students' test results. Instructional methods such as scenarios, problem based learning, case studies, etc. are thought to and often used to improve DM and CT. Although many AT courses within the ATEP curricula have objectives that focus on CT, Fuller (1997) found that few examination questions actually (13-15\%, depending on cohort level) focused on CT. Additionally, in the four programs of this study, all reported they utilized various $\mathrm{CT}$ instructional approaches across the curriculum; however, there appeared to be a gap between utilizing instructional approaches and evaluation of those higher level thinking skills using a written simulation.

With limited use of written simulations as evaluation tools, it appears students are not being objectively evaluated thoroughly on DM skills across the ATEP curricula. While all the ATEP programs in this study reported using a variety of instructional and 
evaluation tools, the scenario evaluations within a clinical experience were usually done by only one observer/evaluator, thus limiting the exposure students had to formative feedback on their evaluation skills. Moreover, many students had limited exposure to and feedback on computer-based simulations. Therefore, for a number of ATEP students involved in this study, the first time they were exposed to the format of the written simulation was during the NATABOC-WS examination, others had been exposed once prior to the national exam during a senior exit examination, and/or others were exposed during only a small portion of the total undergraduate curriculum. Finally, the researcher failed to ask when these evaluations using a written simulation occurred. It may have actually been after this group of seniors enrolled in the classes offering written simulations as evaluations. Care must be taken in generalizing these data because of the low number of institutions $(N=4)$ available for this study. However, future studies investigating why the national exam has such a low pass rate for first time test takers may want to identify at what point the usage of written simulations within ATEP's begins as well as the frequency of their usage across the curriculum.

Although it was reported that the liberal arts schools were using the written simulation evaluation techniques within the curriculum, additional correlations between usage of the written simulation and pass/fail rate could not be calculated due to the low number of participants volunteering results and because only two of the four institutions had seniors taking the NATABOC-WS. The investigator will continue to collect data on NATABOC-WS scores until November which may allow further correlations to be researched, but it appears that although the written simulation is used as an evaluation tool, its use is limited and student exposure to this type of test remains inadequate. 
Again, caution should be taken in generalizing these results as this study only looked at four institutions in the state of West Virginia. Future studies should survey all ATEP accredited programs to validate these results and to investigate if this usage affects pass/fail on the NATABOC-WS.

\section{Hypothesis Three Discussion}

CT in allied health professions has continually focused on longitudinal studies that measure a students $\mathrm{CT}$ at their entry point and again at the exit point of their formalized program. Educational literature has focused on cognitive development and classifications for thinking. Additionally, some educational research has focused on measuring CT for different types of college students, yielding mean averages for certain groups, i. e. medical students, masters' in business administration, nursing, or identifying means for varying cohort levels. The absence of literature in AT may be because of the reliance on other allied health research and curricular models but may also be because AT is still considered by many as a relatively new field and is continuing to expand its educational research. The majority of the research completed in AT has not focused on CT skills in AT.

However, two studies attempted to investigate the idea of AT students' ability to think critically. Leaver-Dunn, et al (2002) found that AT students, when tested with the California Critical Thinking Disposition Inventory (CCTDI), have a predisposition to think critically across the curriculum, but because this was a cross-sectional study, similar to this study, due to the threat of external validity, care must be taken in generalizing these results However, these may be an explanation as to why the AT students in this study outscored the non-AT students at every cohort level and within every subscale. 
Additionally, Walker (2002) compared changes in CT skills in AT as a result of an instructional methodology technique. However, with neither of these researchers identifying if AT students have adequate CT skills or if AT students have different CT levels then other college students; this study appears to have recognized that AT students do have higher critical thinking skills than their college counterparts. This finding may go a long way in continuing to refine how ATEP's design their curricula. However, due to the fact that an unexpected threat to internal validity was that the researcher was unable to obtain a non-ATEP sample from one of the schools, caution should be taken in generalizing these results until further studies can validate these findings.

Even though ATEP students outscored the non-ATEP students in four of the five subscales, inference, deduction, interpretation and evaluation, ATEP students appear to be weaker in the ability to recognizing assumptions. Moreover, the repeated measures ANOVA indicated that all subscales were significant at the $<.01$ level with the major factor with the exception of that same subscale (See Table 5). This indicates that the familywise alpha is also significant for all but one subscale. Furthermore, when looking at effect size, in these repeated measures, all had a low to moderate effect (See Table 5), which parallels most social research, thus decreasing the finding occurred by chance. Finally, with no violations of homogeneity (Box's Test of Equality $=.494)$, the observed covariance matrices were equal across groups.

With athletic trainers (AT) continuing to deal with a variety complex issues requiring the application of higher level thinking processes, the ATEP curricula has focused on many instructional techniques to enhance these skills. During an evaluation of an injury, the AT must discriminate between signs and symptoms of an injury that may 
be considered true or false information (inference). They must have the ability to draw a conclusion based on the information at hand (deduction), as well as be able to examine pros and cons of a treatment and determine if the conclusions are justified (interpretation). Finally, they must have the ability to identify strengths and weaknesses of a treatment on a particular injury and alter it if need be (evaluation of arguments). Recognition of assumptions is an ability of an individual to recognize stated and unstated assumptions or something that is believed to be true without proof. During the evaluation process, the AT is focused on only factual information, and this may be a reason why the ATEP group did not perform as well on this subscale.

Further investigation into ATEP curricular affects on CT is needed. It is unclear if differences in $\mathrm{CT}$ are due to the actual curricular instructional methods or if it is a result of the attrition rate that comes with a formalized admission process. With previous research showing a positive correlation with GPA and CT, further research into GPA and CT in AT should be identified; unfortunately due to poor self-reporting this study could not investigate this variable. While there may be additional factors affecting CT (school, institution type), it appears that AT students possess critical thinking skills that are higher than the non-ATEP population in this study. However, as found in hypothesis one, when comparing AT students' overall mean averages to the mean averages of other college students (Graph 1), AT students are performing at a much lower level (WGCTA Manual) than this researcher expected. Additionally, the mean averages for the non-ATEP group were even lower. Previous literature supports the notion that $\mathrm{CT}$ at every level is poor, and again one may infer that critically thinking in college students is poor (Keeley\& Brown, 1986); however, with only $32.6 \%$ of the total participants requesting their results 
and the researcher finding a positive correlation between requesting results and higher raw scores, it may also be inferred that overall the students in this study did not place much effort into the WGCTA and therefore did not perform well.

\section{Hypothesis Four Discussion}

With a significant finding of ATEP students having higher CT skills then nonATEP students in the college setting, it was important to establish if there was any difference in $\mathrm{CT}$ across the college curricula and if so, where that difference occurred. Most educational literature indicates, via pre and post testing, that the greatest gains for $\mathrm{CT}$ occur in the freshman year and that CT continues to increase with years in school and with maturation (Dressel \& Mayhew, 1954; Maiorana, 1992). While this study was not able to perform pre and post testing for each cohort level for the corresponding cohort year, the cross-sectional study was able to identify some interesting differences and trends.

With the exception of deduction freshman cohort level and recognition at the senior cohort level, the analysis of cohorts (semester hours completed) indicates the ATEP majors scored higher in every subscale. At which level these scores had the largest difference varied for each individual subscale. However, for the non-ATEP group, all five subscales, inference, recognition, deduction, interpretation and evaluation had the greatest differences from the junior to senior cohort level. Thus it could be said that for the non-ATEP group, CT increased with additionally schooling and maturation. This would parallel previous research literature. For the ATEP students, inference had the largest difference from junior to senior year, recognition differed greatly between the sophomore to junior year, deduction and interpretation differences occurred between 
freshmen to sophomore year, while little differences occurred in evaluation across the cohort variable. Thus it could be said that GPA or ATEP admission requirements may affect the deduction and interpretation subscales, while the ATEP curricula may have an affect on the recognition subscale and the college curricula, along with maturation may affect the inference subscale.

Some of the changes that occur from the freshman to the sophomore year may be as a result of attrition. AT, with its formal application process and stringent acceptance guidelines, may only have those students with the highest GPA remaining. Requirements for most ATEP programs are a minimum GPA of 2.5, and although GPA was not analyzed due to insufficient data, previous studies have shown high GPA to be a limitation to CT research. Additionally, if ATEP students are predisposed to think critically, the ATEP sophomore cohort may have had extremely high scores to begin with, and therefore, significant differences may not be identified across cohort levels. Finally, due to the cross-sectional sample, care must be taken in generalizing this study's results.

Nevertheless, this study's results do parallel another cross-sectional, nursing study that found that although no significant differences were found across four cohorts, (Profetto-McGrath, 2003) CT continued to increase and therefore should continue to increase with schooling. Moreover, within AT, the study on CT predisposition indicated that there was no relationship between CCTDI and cohort, semester hours completed or clinical hours of experience. Although the non-ATEP means show little change across time until the senior cohort year and freshman gains pre-post testing were not collected; the researcher could only report that the gains occurred in the senior year and the 
reasoning for this increase is unknown but can be hypothesized that it was due to additional schooling and maturation. Even though the ATEP group's means appear to be consistently higher during the sophomore year, this may be as a result of this group's recent admission into the ATEP program; and therefore, they may be entering with a higher pre-score, thus instead of seeing an improvement across time, there is now a regression toward the mean. Additionally, another possible explanation for the difference is that of the idea of the predisposition to think critically. With the main effect for the major factor being significant as well as the high sophomore score within the ATEP group, additional variables may be affecting ATEP students CT levels.

Ultimately, additional research must continue in this area. Although some threats to internal validity were controlled for, care should be used in generalizing these results as this was a cross-sectional study and therefore shows a picture in time versus changes across time.

\section{Conclusions}

The idea of critical thinking has been around since the days of Aristotle and has continued in education with discussions by Dewey (1918); Bloom (1956); Gagne (1977) and others. Major research by Dressel and Mayhew (1954) investigated CT gains with pre and post testing of various cohorts and majors. Other research has focused on pre and post CT testing on entry-exit testing for specific formalized programs and has been used for programmatic assessment. Educational research focusing on decision making (DM) in teaching parallels the DM processes of clinicians. Additional educational research by Berliner (1987), as well as Livingston and Borko (1989) has looked at DM in teaching; while research by Hill (2002); Girot (2000); Brooks and Sheppard (2002); Misasi, Davis 
and Shapiro (2005) investigated the CT-DM link within allied health fields. Athletic training educational research has only begun to investigate CT.

Fuller (1997) identified ATEP curriculums using CT objectives; however, these curriculums did not test the students abilities to perform higher level thinking skills. Additionally, Leaver-Dunn, et al, (2002) found that within AT, CT dispositions had no relationship between age, gender, race, cohort, GPA, completed semester hours, or clinical experience hours. However, when isolating the means, AT students did have a mild trend toward CT. Additionally, Walker (2002) investigated if instructional methods affected pre and post CT scores and Mcloud, et al, (2005) identified usage of instructional methods and found that curriculums that use scenarios, case studies, and problem based learning techniques appear to be strong predictors of success on pass rates of the NATABOC-WS.

While athletic training educational literature begins to investigate CT, literature, to date, had not investigated the ability of AT students to think critically nor had anyone compared ATEP students' to non-ATEP students' abilities. This study's results indicate that ATEP students do think critically and have a higher critical thinking ability when compared to a group of non-ATEP students. However, the researcher believed that this would be due to the ATEP curriculum; however cohort differences were not significant for ATEP students during the period of peak enrollment of ATEP coursework. Moreover, the high sophomore CT scores may be as a result of the formal application process, thus attrition, due to GPA minimum requirements and course prerequisites, may have eliminated students with lower GPAs and CT scores and may have limited the overall gains throughout the curricula. 
College students had been found to have the greatest $\mathrm{CT}$ gains in the freshman year; therefore, the researcher expected not to have significant gains for the non-ATEP students. Furthermore, when isolating the mean differences, the non-ATEP students CT scores were stable over the freshman, sophomore, and junior year. Senior non-ATEP students' CT scores increased across subscales. This finding is supported by the literature that recognizes $\mathrm{CT}$ is stable over time but that only with additional education and maturation will it be affected.

With the CT abilities of AT students supported by the research, the relevance of its importance is still at question. It is the perception of this researcher as an educator that $\mathrm{CT}$ is important within the educational process. Within allied health it is thought that if students think critically, then they will become strong clinicians, with good decisionmaking skills. However, this CT-DM link continues to require more scrutiny before this concept can be accepted. Other correlation studies have also found no correlation, a weak correlation, or a moderate correlation within AT and other allied health fields. This research did not support a relationship between $\mathrm{CT}$ and DM in AT; however, due to the internal validity issues, additional studies should be conducted.

This idea of the CT-DM link has led to studies (Mcloud, et al) that identified CT instructional methods and the use of these within curriculums to predict success on the NATABOC-WS. However, with the continued poor success of first time test takers, additional evaluation techniques may be the answer and not the instructional methods used. Although this study only looked at four institutions that had a limited number of students eligible to take the NATABOC-WS, the use of curriculums using written simulations across the ATEP curriculum was extremely low. This limits the formative 
and summative feedback students receive during their undergraduate education on their injury evaluation skills. Additionally, this may affect students comfort level and thought process when taking this type of exam and may lead to poor success. Finally, the factor of the overall low percentile scores on the WGCTA may also affect student success on the NATABOC-WS.

Instead of assuming skill transfer from other allied health fields, AT needs to continue to perform its own research to confirm CT and DM within the field. Additional research on the usage of the written simulation with the ATEP curriculum and its relationship to the pass-fail success rate on the NATABOC-WS should also be investigated. Finally, additional research should be done to confirm the ATEP versus non-ATEP CT results of this study in order to substantiate the findings. It is possible that with larger cohort sizes, that the results of this study may have had a Type II error and that additional research may indeed find that cohort levels are significant with CT. That being said, the requirements for MANOVA analysis were met for all but one cell, thus the researcher feels confident in the findings that a Type II error was eliminated 


\section{CHAPTER FIVE}

\section{SUMMARY, CONCLUSIONS AND RECOMMENDATIONS}

\section{Introduction}

The purpose of this chapter is to summarize the findings of the study.

Organizational format will include a summary abstract, conclusions of the results and recommendations for further study.

Abstract

Critical thinking (CT) and decision making (DM) are complex and multifaceted. Student cognition continues to evolve into a complex research area. Due to the complexity, the research in this area is limited. Moreover, when researchers focus on CT, there are controversial issues such as defining, evaluating, and identifying teaching techniques that promote CT. Ennis (1985) has provided a comprehensive definition that most researchers now use. Researchers must remember that standardized tests for evaluating CT have been shown to be valid and reliable (Watson \& Glaser, 1980). Finally, methodological confusion could be decreased with additional research focusing on instructional methods promoting CT. Courses and programs that have been specifically designed to improve general CT have had mixed results. However, in comparison to courses taught in a traditional manner, greater gains in CT scores were found for courses emphasizing problem solving, class participation and inquiry. Athletic Training (AT) curriculum focuses on the application of the problem solving, inquiry, etc. to promote CT within the field; however, there is little evidence that Athletic Training Educational Program (ATEP) evaluates DM skills didactically or clinically. General CT skills in AT must be determined and a correlation determined for the National Athletic 
Trainers' Association Board of Certification - Written Simulation (NATABOC-WS) prior to examining alternative ways of evaluating CT in AT. Since only one piece of research has been done in this area, and the correlation between CT and DM has not been established, this study seems to be an appropriate way to continue this investigation. While many educators in the allied health profession understand the idea of lateral transference by Ausubel, the field of athletic training must continue to do its own research to establish a CT-DM instead of assuming skill transfer from the medical or allied health fields. The correlational methodology compared scores from 11 ATEP seniors' Critical Thinking Appraisal (CTA) and their NATABOC-WS results. Institutions were compared for usage of written simulation evaluations across the curriculum. Finally, 239 college students, 104 non-ATEP students and 135 ATEP students were subjected to a 2X4 MANOVA to identify differences between AT and nonAT majors, as well as identifying differences across all four cohorts.

\section{Conclusions}

Each research hypothesis was tested and the conclusions follow. The Point Biserial was calculated yielding no significant $(r=.1226)$ correlation between the NATABOC-WS (measuring DM in AT) success rate and the WGCTA raw score (measuring CT in ATEP students). Therefore, this research indicates there is no correlation between $\mathrm{CT}$ and DM in AT.. Although the power of this study was a threat to internal validity, the results of this study parallel the results found by Misasi, Davis and Shapiro (2005), who found no correlation between the NATABOC-WS score and the California Critical Thinking Skills Test. Additionally, allied health professionals have not established a strong DM-CT link. Therefore, the literature has yet to establish a 
strong correlation within the allied health field, which may indicate the need for much more comprehensive analysis of the DM-CT link.

With only two institutions investigated utilizing the written simulation across the curriculum and with it being utilized in the required coursework only $11 \%$ of the time, a written simulation evaluation, although used, is not utilized across the ATEP curriculum, and hypothesis two was accepted. In trying to explain the low pass rate for the NATABOC-WS, for a number of students within the ATEP's involved in this study, the first time they were exposed to the format of the written simulation was during the NATABOC-WS examination, others had been exposed once prior to the national exam during a senior exit examination, and/or others were exposed during only a small portion of the total undergraduate curriculum. This may contribute to test anxiety and may therefore be a factor in success rates. Again, care must be taken in generalizing the data because of the low number of institutions $(N=4)$ available for this study.

Analysis using the five subscales (inference, recognition of assumptions, deduction, interpretation and evaluation of arguments) with the fixed variable of major was significant. In conclusion, for hypothesis three, ATEP majors do have higher critical thinking skills compared to non-ATEP college students and thus hypothesis three was accepted. ATEP curriculums appear to affect CT. However, it is unclear if it is due to the actual curricular instructional methods or if it is a result of the attrition rate that comes with a formalized admission process or other selection factors. While there may be other factors that affect CT (school, institution type), it appears that not only do AT students possess critical thinking skills that are higher then the non-ATEP population, but that both groups have weak CT abilities overall. Although several students did perform well, 
those requesting scores placed an emphasis on their results and performed better than students who placed no meaning on the appraisal. Further investigation may be indicated since both groups had an overall low mean average and this may be a factor in the absence of a DM-CT link for AT.

Moreover, the analysis of the five subscales looking at the interaction of major factor and time factor (cohort level) was not significant. Additionally, it appears that the non-ATEP group consistently increased in CT skills from junior to senior year, with only a significant finding between freshman and senior year. ATEP students had inconsistent differences across cohorts, with some of the greatest increases occurring at the freshman to sophomore year, indicating admission may play a factor. Although other subscales had increases from sophomore to junior year and junior to senior year, these were not significant to infer that the ATEP curriculum affected the levels of CT. With no significance found in the interaction, hypothesis four was not accepted. Again, although it appears that college does, in fact, affect CT, it may actually be as a result of the passage of time and maturation. This study attempted to control for that variable by utilizing a cross-sectional sample. At the same time, with CT dispositions being stable over time, it seems that only with prolonged educational exposure or with specific instructional methods will CT skills be affected. This is indicated by the fact that for most of the nonATEP group, there was an overall increase in CT only after the senior year. Again with ATEP students, the sophomore students' higher scores are unaccounted for. It is unclear if the ATEP instructional methods affected CT levels or if the admission requirements eliminated weaker students with lower CT skills. This may also lend support to the previous study on CT predispositions, and the difference lies in the fact that ATEP 
students do indeed have a slight by mild trend toward thinking critically. Finally, although ATEP students had higher CT scores than their non-ATEP counterparts, it is unclear by these results if AT students have strong CT abilities. Additionally, the lack of a non-ATEP sample from one institution may or may not have affected the results. The significance of this may be further intensified by the fact that the institution was a liberal arts school and not a larger public institution. Further studies should look at the differences between private liberal arts schools and public schools to confirm previous studies that have indicated that students who attend liberal arts institutions have higher CT skills.

\section{Recommendations}

Athletic trainers evaluate the athlete's injury, make decisions regarding injury management, provide first aid and treatment, establish rehabilitation protocols, and evaluate the outcomes of their decisions. To practice effectively, they must think critically and make appropriate decisions. As educators make curricular changes to improve DM in AT, instructional methods to develop CT continue to be proposed as a means to achieve this goal. This idea is based on the assumption that there is a DM-CT link that this researcher feels has not been established in the literature. Additionally, issues continue to increase regarding the poor performance of students on the NATABOC-WS. This poor performance by graduates continues to be a focus for educators in improving their own programs and striving to develop strong clinicans. Although this poor result may be due to test anxiety, it may also be as a result of students being novices at taking written simulation type exams or may be related to the AT students' overall weak ability to think critically. 
Correlation studies have consistently yielded moderate to weak or no correlation between $\mathrm{CT}$ and DM. Additionally, there are few studies that have investigated this relationship in AT. Moreover, further investigation is needed in the relationship between CT skills and grade point average, as well as other academic demographic data. A more in depth analysis could be used to identify correlations with CT. If CT and DM and other academic variables are indeed linked, then it would lead educators to stress more CT instructional methods across the AT curriculum; however, this is typically the current model by many. Athletic training programs stress these instructional models without a firm basis as to why. If these methodologies are being used consistently, then why are the test scores still low? An additional study surveying all ATEP curriculums on their use of evaluation of DM in AT is appropriate. Identifying use of written simulations in the didactic curriculum, as well as identifying the use of a comprehensive scenario evaluations of an injury within the clinical portion of the curriculum, may be of assistance in determining if exposure to these types of formal evaluations within the ATEP affect anxiety and/or comfort level with the NATABOC-WS. Additionally, researchers may want to investigate the relationship between those students who have been exposed to the WS with those who have had limited or no exposure to this type of evaluation. In essence, then at some point should we determine which has a greater effect on $\mathrm{CT}$ and $\mathrm{DM}$ in $\mathrm{AT} . . . ?$ Is it $\mathrm{CT}$ instructional methods or DM evaluation procedures?

With established means for nursing, much of the CT literature within the allied health fields has looked at entry-exit data. Athletic training had investigated predispositions to think critically; however, this is the first study in AT to identify CT in 
AT and if ATEP students think any differently then other college students. This study should be replicated to ensure efficacy; furthermore, it has not been established by this study that the ATEP curriculum is the reason why this occurs. Research focusing on specific groups of majors may yield a more relevant finding then the use of random majors. Additional research should be done to identify if institution type factors affect CT in ATEP versus non-ATEP students. This study was unable to obtain a non-ATEP group from one of the liberal arts institutions and therefore a comparison between institution types could not be made. Other questions they may be answered by research are if ATEP students from liberal arts schools have a higher passing rate on the NATABOC-WS then public 4-year institutions, do liberal arts ATEP programs evaluate with WS and scenario comprehensive injury evaluations more than the larger public institutions, and finally, is there a relationship between those programs that use a WS evaluation in their undergraduate curriculum and the students success on the NATABOCWS. .

Finally, it was not established when ATEP students greatest increases in CT occur. A possible limitation to this may have been the lower number of participants in each group's cohort; however, with all but one group meeting the requirement for a MANOVA analysis, the researcher is confident that the findings were not affected by this internal validity variable. To confirm these results, additional entry-exit testing could be done with the ATEP group to establish CT levels for ATEP students, as well as more specific longitudinal studies within the ATEP testing at each cohort level with larger cohort sizes. Other recommendations for further studies may incorporate the idea of alternative definitions for cohort, such as year in school or clinical hours completed, etc. 
Additionally, these ATEP groups should continue to be compared to other college groups.

Although this study supported some of the hypotheses, AT must continue to increase its educational research. Athletic training educational research should be encouraged to establish a variety of instructional methods and evaluation procedures that encourage independent learning. The higher education experience must continue to develop higher level thinking skills, and it is clear that further work in AT must be done in developing tools to measure $\mathrm{CT}$ in $\mathrm{AT}$ and its application in to practice. This study has probably created more questions then it answered; nevertheless, the research has been an important step in beginning the process and the conversation of the importance of $\mathrm{CT}$ in AT. 


\section{REFERENCES}

Annual Examination Report. (1999). NATABOC Certification Update, summer, 1, 3-5. Annual Examination Report. (2000). NATABOC Certification Update, summer, 1, 3-5. Annual Examination Report. (2001). NATABOC Certification Update, summer, 1, 3-5. Annual Examination Report. (2002). NATABOC Certification Update, summer, 1, 3-5.

Ausubel, D., Novack, J., \& Hanisian, H. (1978). Educational psychology: A cognitive view. New York, NY: Holt, Reinhart and Winston.

Bandura, A. (1986). Social foundations of thought and action: A social cognitive theory. Englewood Cliffs, NJ: Prentice Hall.

Banta, T. (1993). Toward a plan for using national assessment to ensure continuous improvement of higher education. Journal of General Education, 42, 33-58.

Bartlett, D., \& Cox, P. (2002). Measuring change in students' critical thinking ability: Implications for health care education. Journal of Allied Health, 31, 64-69.

Bauwens, E., \& Gerhard, G. (1987). The use of the Watson Glaser Critical Thinking Appraisal to predict success in a baccalaureate nursing program. Journal of Nursing Education, 26, 278-281.

Berliner, D. (1987). In pursuit of the expert pedagogue. Educational Researcher, 15(7), $5-13$.

Beyer, B. K. (1984). Improving thinking skills-practical approach. Phi Delta Kappan, April, 556-560.

Bloom, B. S. (1956). Taxonomy of educational objectives. New York, New York: David McKay Company, Inc. 
Brooks, K., \& Shepherd, J. (1990). The relationship between clinical decision-making skills in nursing and general critical thinking abilities of senior nursing students in four types of nursing programs. Journal of Nursing Education, 29, 391-399.

Cairns, M. A. (2000). Which should I teach: Critical thinking or the facts? Can I do both? www.cewl.com.

Castle Worldwide, Inc. NATABOC Test Development. (1999). NATABOC test development. Retrieved January 21, 2004, from http://www.nataboc.org/atc/docs/other/.

Champagne, A. B., Gunstone, R. F. \& Kloper, L. E. (1985). Instructional consequences of students' knowledge about physical phenomena. In L.T. West and A.L. Pines (Eds.), Cognitive structure and conceptual change (pp. 61-90). Orlando, FL: Academic.

Clark, R., \& Harrelson, G. L. (2002). Designing instruction that supports cognitive learning processes. Journal of Athletic Training, 37, S152-S159.

Coker, C. A. (2000). Consistency of learning styles of undergraduate athletic training students in the traditional versus the clinical setting. Journal of Athletic Training, 35, $441-444$.

Davies, I. K. (1976). Objectives in curriculum design. Berkshire, England: McGraw-Hill Book Company (UK) Limited.

Delforge, G., \& Behnke, R. (1999). The history and evolution of athletic training education in the United States. Journal of Athletic Training, 34, 53-61.

Deforges, C. (1995). How does experience affect theoretical knowledge for teaching? Learning and Instruction, 5, 385-400. 
Donnelly, F. C., Helion, J., Fry, F. (1999). Modifying teacher behaviors to promote critical thinking in K-12 physical education. Journal of Teaching in Physical Education, 18, 199-215.

Doyle, W. (1986). Classroom organization and management. In M. Whittrock (Ed.), Handbook of research on teaching (pp.392-431). New York: MacMillian.

Dressel P., \& Mayhew, L. (1954). General education: Explorations in evaluation. Westport, CT: Greenwood Press.

Ennis, R. (1989). Critical thinking and subject specificity: clarification and needed Research. Educational Researcher, 18, 4-10.

Ennis, R. \& Chen, A. (1993). Domain specifications and content representativeness of the revised Value Orientation Inventory. Research Quarterly for Exercise and Sport, 64, 436-446.

Fancione, N., Fancione, P. \& Sanchez, C. (1994). Critical thinking disposition as a measure of competent clinical judgment: the development of the California Critical Thinking Disposition Inventory. Journal of Nursing Education, 33, 345-350.

Fuller, D. (1997). Critical thinking in undergraduate athletic training education. Journal of Athletic Training, 32, 242-247.

Gadzella, B., \& Baloglu, M. (2003). Psychometric properties of Watson-Glaser Critical Thinking Appraisal for a sample of education majors. Psychological Reports, 92, $1249-1254$

Gagne, R. M. (1977). The conditions of learning. New York, NY: Holt, Rinehart, \& Winston. 
Girot, E. (2000). Graduate nurses: critical thinkers or better decision makers? Journal of Advanced Nursing, 31, 288-297.

Graber, K. (2001). Research on teaching physical education. In V. Richardson (Ed.), Handbook on research on teaching $\left(4^{\text {th }} \mathrm{ed}\right)$ (pp. 421-519). Washington, DC: American Educational Research Association.

Gross, Y., Takazawa, E., \& Rose, C. (1987). Critical thinking and nursing education. Journal of Nursing Education, 26, 317-323.

Harrelson, G. L. \& Leaver-Dunn, D. (2002). Using the experiential learning cycle in clinical instruction. Athletic Therapy Today, 7,(5), 23-27.

Heiman, G. W. (2003). Basic Statistics for the Behavioral Sciences. $\left(4^{\text {th }}\right.$ ed.) Boston, MA: Houghton Mifflin Publishing Co.

Heinrichs, (2002). Problem-based learning in entry-level athletic training professionaleducation programs: A model for developing critical thinking and decisionmaking skills. Journal of Athletic Training, 37, S189-S198.

Hickman, J. (1993). A critical assessment of critical thinking in nursing education. Holistic Nurse Practice, 7, 36-47.

Hill, T. (2002). The relationship between critical thinking and decision-making in respiratory care students. Respiratory Care, 47, 571-577.

Jones, E., \& Ratcliff, G. (1993). Critical thinking skills for college students. ERIC Document No. 358772.

Keeley, S. M., \& Browne, M. N. (1986). How college seniors operationalize critical thinking behavior. College Student Journal, 20, 389-395. 
Konin, J. G., Amato, H. K., \& Brader, H. (2002). Incorporating the Renne Test into a learning-over-time model. Athletic Therapy Today, 7,(5), 12-17.

Lacey, C. (1987). Professional socialization of teachers. In M.J. Durkin (Ed.), The international encyclopedia of teaching and teacher education (pp. 634-645). Oxford: Pergamon.

Leaver-Dunn, D., Harrelson, G., Martin, M. \& Wyatt, T. (2002). Critical thinking predisposition among undergraduate athletic training students. Journal of Athletic Training, 37, S147-S151.

Leinhardt, G., Young, K-M., \& Merriman, J. (1995). Commentary: Integrating professional knowledge: The theory of practice and the practice of theory. Learning and Instruction, 5, 401-408.

Lesback-Wiksten, D., Patterson, P., Antonio, K., De La Cruz, D., \& Buxton, B. P. (1998). The effectiveness of an interactive computer program versus traditional lecture in athletic training education. Journal of Athletic Training, 33, 238-243.

Livingston, C., \& Borko, H. (1989). Expert-novice differences in teaching: A cognitive analysis and implications for teacher education. Journal of Teacher Education, 40, 3642.

Maiorana, V. P. (1992). Critical thinking across the curriculum: Building the analytical classroom. Bloomington, Indiana: EDINFO Press.

Marzano, R. J., Brandt, R. S., Hughes, C. S., Jones, B. F., Presseisen, R. Z., Rankin, S. C., \& Suhor, C. (1989). Dimensions of thinking. Alexandria, Virginia: Association for Supervision and Curriculum Development. 
Mayer, R. E. \& Whittrock, M. C. (1996). Problem solving transfer. In D.C. Berliner \& R.C. Calfee (Eds.). Handbook of educational psychology (pp.47-62). Simon \& Scheuster Macmillian.

McBride, R. E. (1992). Critical thinking-an overview with implications for physical education. Journal of Teaching in Physical Education, 91, 11, 112-125.

McCarthy, P., Schuster, P., Zehr, P., \& McDougal, D. (1999). Evaluation of critical thinking in a baccalaureate nursing program. Journal of Nursing Education, 38, 142144.

McLoda, T. A., Johnston, E. L., \& Hansen, A. J. (2005, January). Instructional approaches to encourage critical thinking in undergraduate athletic training education. Poster session presented at the bi-annual Athletic Trainers' Educator Conference, Del Lago, TX.

Mensch, J. M., \& Ennis, C. D. (2001). Student's educational experiences in CAAHEPAccredited athletic training programs [Abstract]. Journal of Athletic Training, 36, S45.

Miller, C. (1990). Higher-order thinking: an integrated approach for your classroom. Vocational education journal, October, 26-28.

Miller, D. A., Sadler, J. Z., Mohl, P. C., \& Melchiode, G. A. (1991). The cognitive context of examinations in psychiatry using bloom's taxonomy. Medical Education, $25,480-484$.

Miller, M. (1992). Outcomes evaluation: Measuring critical thinking. Journal of Advanced Nusing, 17, 1401-1407. 
Misasi, S. P., Davis, C. F., \& Shapiro, S. (2005, January). Critical thinking skill level and success on the NATABOC written simulation examination. Poster session presented at the bi-annual Athletic Trainers' Educator Conference, Del Lago, TX.

National League for Nursing, (2002). Criteria and guidelines for the evaluation of baccalaureate and higher degree programs in nursing. Publication \#15-2474. New York, NY: National League for Nursing.

Norris, S. P. (1985). Synthesis of research on critical thinking. Educational Leadership, May, 42-45.

Ocansey, R. T-A., Chepyator-Thomson, J. R., Kutame, M. A. (1992). Promoting critical thinking in student teaching practice. Journal of Physical Education, Recreation and Dance, 65, 66-69.

Parker, W. C. (1984). Developing teachers' decision making. Journal of Experimental Education, 220-226.

Pascarella, E. T. (1989). The development of critical thinking: Does college make a difference? Journal of College Student Development, 30, 19-26.

Pascarella, E., Bohr, L., Nora, A., \& Terenzini, P. (1996). Is differential exposure to college linked to the development of critical thinking? Research in Higher Education, $37,159-174$.

Paul, R. W. (1985). Bloom's taxonomy and critical thinking instruction. Educational Leadership, May, 36-39.

Payne, V. G. \& Isaacs, L. D. (1999). Human motor development: A lifespan approach. Mountainview, CA: Mayfield Publishing. 
Payton, O. P. (1984). Clinical reasoning process in physical therapy. Physical Therapy, 65, 924-928.

Pearsall, M.K. (1992). In National Science Teachers Association (Ed.), Scope, sequence, and coordination of secondary school science: Volume II-research related, pp. 166168.

Peer, K. S., \& McClendon, R. C. (2002). Sociocultural learning theory in practice: Implications for athletic training educators. Journal of Athletic Training, 37, S136S140.

Platt, L. S., Sammarone-Turocy, P., \& McGlumphy, B. E. (2001). Preadmission criteria as predictors of academic success in entry-level athletic training and other allied health educational programs. Journal of Athletic Training, 36, 141-144.

Profetto-McGrath, J. (2003). The relationship of critical thinking skills and critical thinking dispositions of baccalaureate nursing students. Journal of Advanced Nursing, $43,569-577$.

Reiber, L.P. (1991). Computer-based microworlds: A bridge between constructivism and direct instruction. ERIC Document Reproduction Service, No. ED335007.

Rovengo, I. (1991). A participant-observation study of knowledge restructuring in a fieldbased elementary physical education methods course. Research Quarterly for Exercise \& Sport, 62, 205-212.

Rovengo, I. (1994). Teaching within a curricular zone of safety: School culture and the situated nature of student teachers' pedagogical content knowledge. Research Quarterly for Exercise \& Sport, 65, 269-279. 
Schommer, M. (1990). Effects of beliefs about the nature of knowledge on comprehension. Journal of Educational Psychology, 82, (3), 498-504.

Schommer, M., Crouse, A., \& Rhodes, N. (1992). Epistemological beliefs and mathematical text comprehension: Believing it's simple doesn't make it so. Journal of Educational Psychology, 84,_435-443.

Schwager, S., Labate, C. (1993). Teaching for critical thinking in physical education. Journal of Physical Education, Recreation, and Dance, 64, 24-27.

Schwartz, R. W., Donnelly, M. B., Nash, P. P., \& Young, B. (1992). Developing student' Cognitive skills in a problem-based surgery clerkship. Academic Medicine, 67, 694698.

Scott, J., Market, R., \& Dunn, M. (1998). Critical thinking:change during medical school and relationships to performance in clinical clerkships. Medical Education, 32, 14-18.

Slaughter, D. S., Brown, D. S., Gardner, D. L., Perritt, L. J. (1989). Improving Physical therapy students' clinical problem-solving skills: an analytical questioning model. Physical Therapy, 69, 441-447.

Songer, N.B. \& Linn, M.C. (1992). Students' views of science influence knowledge integration. In National Science Teachers Association (Ed.), Scope, sequence, and coordination of secondary school science: Volume II-research related, pp.195-203.

Spiro, R. J., Vispoel, W. P., Schmitz, J. G., Samarapungavan, A., \& Boerger, A. E. (1987). Knowledge acquisition for application: Cognitive flexibility and transfer in complex domains. In B.K. Britton \& S.M. Glynn (Eds.), Executive control processes in reading, pp. 177-199. 
Sullivan, E. (1987). Critical thinking, creativity, clinical performance, and achievement in RN students. Nurse Educator, 12(2), 12-16.

Swann, E., \& Walker, S. E. (2001). Interpersonal communication of the athletic training clinical instructor [Abstract]. Journal of Athletic Training, 36, S48.

Tillema, H. H. (1995). Changing the professional knowledge and beliefs of teachers: A training study. Learning and Instruction, 5, 291-318.

Tsui, L. (1998). A Review of Research on Critical Thinking. ASHE Annual Meeting Paper. ERIC Document No. 427572.

Vaughan-Wrobel, B., O’Sullivan, P., \& Smith, L. (1997). Evaluating critical thinking skills of baccalaureate nursing students. Journal of Nursing Education, 36, 485-488.

Walker, S. E. (2002). The effects of writing skills on the critical thinking skills of undergraduate entry-level athletic training students [Abstract]. Journal of Athletic Training, 37, S79.

Wall, J.G. (1954). An analytic study of critical thinking among college freshman. Dissertation.

Watson, G., \& Glaser, E. M. (1980). Critical thinking appraisal manual. Cleveland, OH: Psychological Corporation. 
Appendix A

IRB APPROVAL 


\section{WestVrrginiaUniversity}

School of Physical Education

February 28, 2005

\section{MEMORANDUM}

TO: Wanda Swiger

FROM: Andrew Hawkins

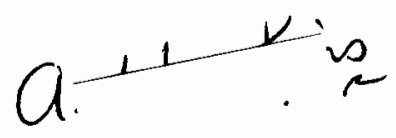

School Reviewer for Exempt Research

RE: Application for Exemption

I have reviewed and approved your application for exemption for your research project entitled:

A Correlation Between Critical Thinking Skills and Decision Making

Skills in Athletic Training and the Differences that Occur Across

The Curriculum

This exemption will remain in effect on the condition that the research is carried out exactly as described in the application.

Best wishes for the success of your research.

AH:cas 


\section{Application for Exemption}

Approval from the IRB staff must be received prior to beginning the research described below. Please type all responses and submit this form with original signatures. All investigators must complete Ethics Training before an approval will be granted.

1. Title of study:

A correlation between Critical Thinking skills and Decision Making skills in athletic training and the differences that occur across the curriculum.

2. Investigators (list all investigators, principal investigator first; attach additional sheets if necessary):

\begin{tabular}{|c|c|c|c|c|}
\hline Name & Signature & Dept/College & Address & Tel No \\
\hline Wanda Swiger & $7^{2}$ & PETE & 75 W. Lincoln St & 304-473-0296 \\
\hline & $\omega$ & & Buckhannon, WV & \\
\hline Name or initials & & & Ethics Training & HIPAA Training ${ }^{2}$ \\
\hline WSS/wos & & YES if training has been completed & & \\
\hline (w) & ${ }^{T}$ Ethics training hit & Thww wvu edu/rclint/ethi tra htm & Feb 13,2005 & \\
\hline & HIPAA info: & tD./www. wvu.edu/ rc/ind/index htm & & Feb 13, 2005 \\
\hline
\end{tabular}

3. Estimated period of project or of human subject involvement: Starting date: $\quad$ Mar 10, Ending date: July 1,2005

\begin{tabular}{ll} 
Estimated period of project or of human subject involvement: & Starting date: $\begin{array}{l}\text { Mar 10, } \\
2005\end{array}$ \\
\cline { 2 - 2 }
\end{tabular}

4. Reason for conducting research
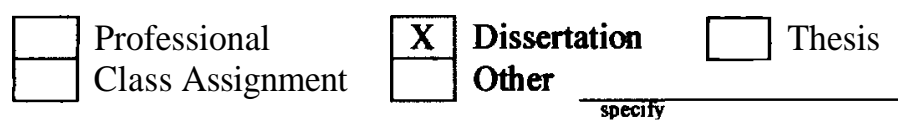

5. Source of finding (if applicable)

NONE

6. Number of projected subjects $\quad 400 \quad$ Number of projected records or data files 400

7. $\quad$ This research involves (check all that apply — see attached "Exempt Research" page):
$\square$ a
Collection or study of existing data, documents, records or specimens, recorded without identifiers
$\square$ b Normal educational practices conducted in established or comm
$\mathrm{X}$ c Educational tests (cognitive, diagnostic, aptitude, achievement)
$\mathrm{d}$ Observation of public behavior
$[\mathbf{X}]$ e Surveys, interviews or hand-outs for subjects over 18
(use age ranges. not actual age. for demographic information): 


\section{Mail $\square$ Telephone $\mathrm{X}$ Person-to-person}

Any possibility of identifying a subject (discuss in cover letter)

The possibility that the subject's responses or conduct (if they became public) may place the subject at risk of criminal or civil liability or be damaging to the subject's financial standing or employability

Sensitive aspects of personal behavior (for example: illegal conduct, drug use, sexual behavior or use of alcohol)

Investigator's participation in activities being observed

Only surveys or interviews of elected or appointed public officials or candidates for public office

k Audiotaping

1 Children under age 18 (see Chapter II of the Guidelines)

Note: Interviews and surveys with children are never exempt.

$\mathrm{m}$ Food tasting and evaluation

n Research and demonstration projects

o Access to protected health information (PHI) (See HIPAA requirements: $\underline{\text { http://www.wvu.edu/ rc/irb/index.htm) }}$

8. Goal of research

To identify if there is a relationship between critical thinking and decision making skills within the field of athletic training and to identify any differences in critical thinking that may occur across the curriculum of athletic training when compared to other college students.

\section{Revised Dec 2003}

9. Explanation of procedures involved in research

Step one: Administer the Watson Glaser Critical Thinking Appraisal to all four-cohort athletic training majors from six accredited West Virginia colleges/universities. Step two: Administer the WGCTA to six general studies classes of non-athletic training majors, having all four cohorts, within the same institutions. Step three: Administer demographic questionnaire to the same two groups. Step four: Administer a program questionnaire and a follow-up interview to the program directors of the same six institutions. Step five: Collect national certification scores of the written simulation examination from the senior athletic training majors.

10. Explanation of known risks to human subjects

None

11. Explanation of how records will be kept 
$\square$ telephone text (including introductory remarks as in a cover letter-see above)

$\mathrm{X}$ cover letter

permission from external institution, on their letterhead (if applicable)

I have reviewed the above information and recommend this study for exemption.

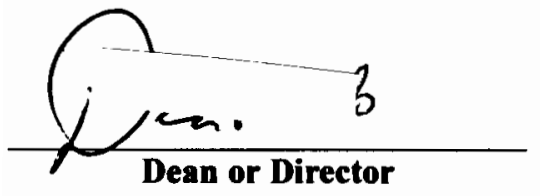

Dean or Director

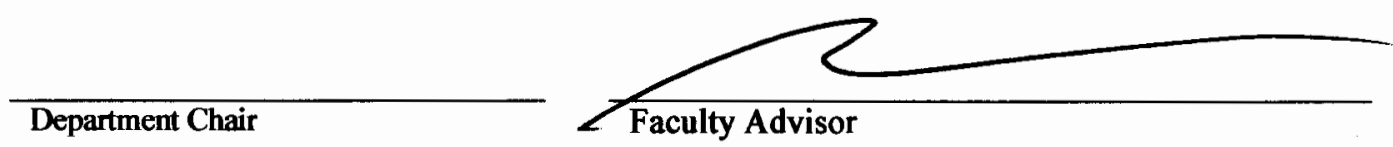

Department Chair

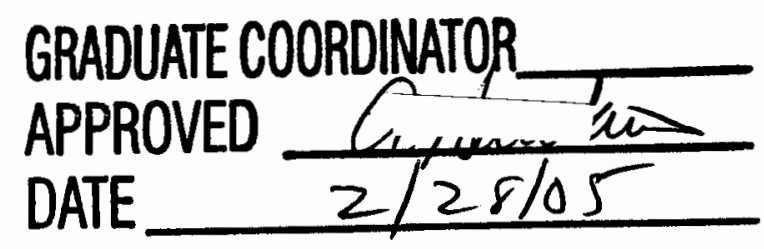


Appendix B

LETTER TO PARTICPANTS 


\section{West VirginiaUniversity}

School of Physical Education

\section{Correlation of critical thinking and decision making and changes in critical thinking across the curriculum}

This study is being conducted by Wanda Swiger in the Department of Physical Education at West Virginia University for completion of her doctoral work. The purpose of this study is to evaluate the changes in critical thinking across different cohorts (classes, i. e. freshman, sophomore, junior, senior) in different content (majors) areas. In addition, seniors majoring in Athletic Training, who are sitting for the National Athletic Trainers' Association Board of Certification Examination (NATABOCWS examination), will report this score so that the investigator can correlate the relationship between critical thinking scores and decision-making scores.

You are being asked to take a critical thinking appraisal and complete a demographic information sheet related to your college education (taking approximately 45-50 minutes). Only seniors within the athletic training education program will provide additional information via the written simulation test score results from their NATABOC Examination. I understand that I will be asked to fill out a questionnaire regarding age, gender, class rank, major, GPA, etc. This will take approximately 5 minutes. Athletic training education program directors will provide demographic information regarding their school and their program and a follow-up interview for any follow-up questions.

You do not have to answer all the questions and you will have the opportunity to see the demographic/appraisal before agreeing to participate. In addition, all test scores will be coded to protect confidentiality. Finally, participation is voluntary, and while there may be no direct benefits to you, you may request your test results to the critical thinking appraisal.

Possible benefits that may result from my participation include improving the understanding and awareness of critical thinking and decision-making and the importance of both as a professional. The study will allow researchers to gain a better understanding of the importance of critical thinking skills within higher education and specifically within athletic training. The study may also allow researchers to gain a better understanding of how athletic training educational programs evaluate decision-making and the improvement of evaluation techniques within the field of athletic training education.

For more information about this research, contact Wanda Swiger at 304/473-8002 or Dr. Robert Wiegand at 304/293-3295. For information regarding you rights as a research subject, contact the Office of Research Compliance at 304/293-7073.

Thank you for your time.

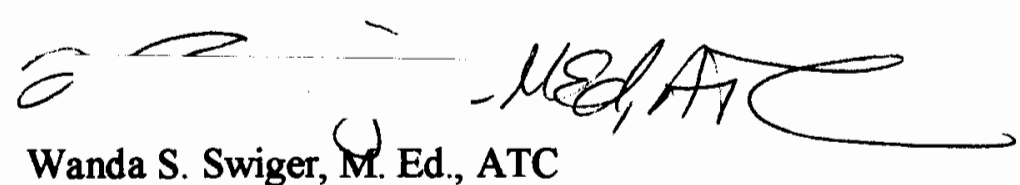




\section{Appendix C}

Pre-Interview Demographic questionnaire for ATEP directors

School name:

Type of institution: ___ Private ___ Public Division: ___ I _ _ _ II ___ III Average number of students enrolled in the college/university:

Average number of students enrolled in ATEP:

Average number of ATEP per cohort:

Average number of freshman applying into the ATEP

Number of major courses required by ATEP

Credits

Types of evaluation used: which of the following do you use? (You will be asked to provide specifics to which course and in what cohort year. Syllabi for coursework denoting usage may be helpful.)

Scenarios

Case studies

Written simulations (computer or latent marker)

Clinical simulations

Computer-assisted instruction

Problem based learning activities

Clinical rotations

Comprehensive evaluations

Other 


\section{Appendix D}

\section{Interview Questions}

Types of evaluation used: which of the following do you use?

Scenarios

Case studies

Written simulations (computer or latent marker)

Clinical simulations

Computer-assisted instruction

Problem based learning activities

Clinical rotations

Comprehensive evaluations

Other

Where in the curriculum do you use (classes/cohort year)

* Number of classes specifically using written simulation as an evaluation

Is the simulation computer-based $\mathbf{Y}$ or $\mathbf{N}$ (circle one)

Is the simulation pen-to-paper $\mathbf{Y}$ or $\mathbf{N}$ (circle one)

* Does your program require a senior exit examination $\mathbf{Y}$ or $\mathbf{N}$ (circle one)

If yes, do you use a written simulation as part of the exit examination $\mathbf{Y}$ or $\mathbf{N}$ (circle one)

Is the simulation for the exit exam computer-based $\mathbf{Y}$ or $\mathbf{N}$ (circle one)

Is the simulation pen-to-paper $\quad \mathbf{Y}$ or $\mathbf{N}$ (circle one)

**** Please provide syllabi of only those courses that use a written simulation as a type of evaluation. 


\section{Appendix E \\ Demographic Questionnaire for students}

Student rank: (fresh, soph, jr, sr)

Semester hours completed:

Department:

Major:

Gender:

Race:

Date of Birth:

College GPA:

H.S. GPA:

ACT/SAT Scores:

FOR ATEP STUDENTS ONLY: Approximate number of clinical semesters completed to date:

FOR ATEP SENIORS ONLY: Please list the date you will be sitting for the NATABOC-WS examination: 


\section{APPENDIX F}

Sample Watson Glaser Critical Thinking Appraisal 


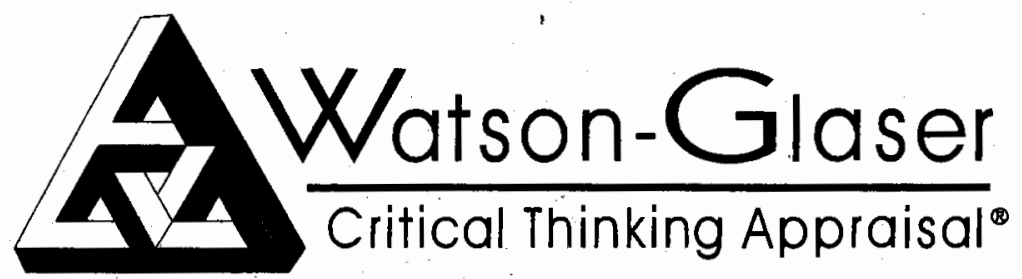

\section{FORM B}

\section{DIRECTIONS}

This booklet contains five types of tests designed to find out how well you are able to reason analytically and logically. Each test has separate directions that should be read carefully.

Do not turn this page.until instructed to do so.

Do not make any marks in this test booklet.

All answers are to be marked on the separate answer sheet provided. Use a sharp No. 2 pencil to mark your answers. If you wish to change an answer, be sure to erase your old answer completely. 


\section{TEST 1: INFERENCE}

\section{DIRECTIONS}

An inference is a conclusion a person can draw from certain observed or supposed facts. For example, if the lights are on in a house and music can be heard coming from the house, a person might infer that someone is at home. But this inference may or may not be correct. Possibly the people in the house did not turn the lights and the radio off when they left the house.

In this test, each exercise begins with a statement of facts that you are to regard as true. After each statement of facts you will find several possible inferencesthat is, conclusions that some persons might draw from the stated facts. Examine each inference separately, and make a decision as to its degree of truth or falsity.

For each inference you will find spaces on the answer sheet labeled $T, P T, I D, P F$, and F. For each inference make a mark on the answer sheet under the appropriate heading as follows:

$T$ if you think the inference is definitely TRUE; that it properly follows beyond a reasonable doubt from the statement of facts given.

PT if, in the light of the facts given, you think the inference is PROBABLY TRUE; that it is more likely to be true than false.

iD if you decide that there are INSUFFICIENT DATA; that you cannot tell from the facts given whether the inference is likely to be true or false; if the facts provide no basis for judging one way or the other.

PF if, in the light of the facts given, you think the inference is PROBABLY.FALSE; that it is more likely to be false than true.

$F$ if you think the inference is definitely FAISE; that it is wrong, either because it misinterprets the facts given, or because it contradicts the facts or necessary inferences from those facts.

Sometimes, in deciding whether an inference is probably true or probably false, you will have to use certain commonly accepted knowledge or information that practically every person has. This will be illustrated in the example that follows.

Look at the example in the next column; the correct answers are indicated in the block at the right.

\section{DXNPLE}

Two hundred students in their early teens voluntarily attended a recent weekend student conference in a Midwestern city. At this conference, the topics of race relations and means of achieving lasting world peace were discussed, since these were the probleins the students selected as being most vital in today's world.

1. As:a group, the students who attended this conference thowed a keener interest in broad rocial problems than do most other students in their early teene.

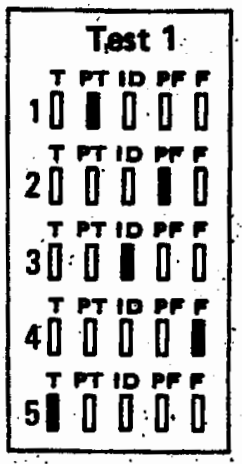

2. The majority of the students had not prevloualy discussed the conference topics in their schools.

3. The students came from all sections of the country.

4. The students discussed mainly labor relation probleins.

5. Some teenage. students felt it worthwhile to discuss problems of race relations and ways of achieving world peace.

In the above example, inference 1 is probably true (PT) because (as is common knowledge) most people in their early teens do not show so much serious concern with broad social problems. 'It cannot be considered definitely true from the facts given because these facts do not tell how much concern other young teenagers may have. It is also possible that some of the students volunteered to attend mainly because they wanted a weekend outing.

Inference 2 is probably false (PF) because the students' growing awareness of thèse topics probably stemmed at least in part trom discussions with teachers and classmates.

There is no evidence for inference 3 . Thus there are insufficient data (ID) for making a judgment on the matter.

Inference 4 is definitely false (F) because it is given in the statement of facts that the topics of race relations and means of achieving world peace were the problems chosen for discuission,

Inference 5 necessarily follows from the given facts; it therefore is true (T).

In the exercises that follow, more than one of the inferences from a given statement of facts may be true (I), or false (F), or probably true (PT), or probably false (PF), or have insufficient data (ID) to warrant any conclusion. Thus you are to judge each inference independently:

Make a heavy black mark in the space under the heading that you think best describes each inference. If you change an answex, erase it thoroughly. Make no extra marks on the answer sheet. 


\section{TEST 2: RECOCNITION OF ASSUMPTIONS}

\section{DURECTIONS}

An assumption is something presupposed or taken for granted. When you say, "I'll graduate in June," you take for granted or assume that you will be alive in June, that your school will judge you to be eligible for graduation in June, and similar things.

Below are a number of statements. Each statement is followed by several proposed assumptions. You are to decide for each assumption whether a person, in making the given statement, is really making that assumptionthat is; taking it for granted, justifiably or not.

If you think that the given assumption is taken for granted in the statement, make.a heavy black mark under "ASSUMPTION MADE" in the proper place on the answet sheet. If you think the assumption is not necessarily taken for granted in the statement, blacken the space under "ASSUMPTION NOT MADE." Remember to judge each assumption independently.

Bèlow is an example. The block at the right shows. how these items should be marked on the answer sheet.

\section{EXAMPLE}

Statement: "We need to save time in getting there 10 we'd better go by plane."

Proposed assumptions:

1. Going by plane will take less time than going by some other means of transportation. (It is assumed in the statement that the greater speed of a plane over the speieds of other means of transportation will enable the group to reach its destination in less time.)

2. There is plane service available to us for at least part of the distance to the destination. (This is necessarily assumed in the etatement since, in order to save time by plane, it muat be possible to go by plane.)

3. Travel by plune is more convenient than travel by train. (This asamption is not made in the statemerit-the statement has to do with saving time, and says nothing about convenience or about any other specific mode of travel.)

\section{TEST 3: DEDUCTION}

\section{DIRECTIONS}

In this test, each exercise consists of several statements (premises). followed by several suggested conclusions. For the purposes of this test, consider the statements in each exercise as true without exception. Read the first conclusion beneath the statements. -If you think it necessarily. follows from the statements given; make a heavy black mark under "CONCLUSION FOLLOWS" in the proper place on the answer sheet. If you think it is not a neces. sary conclusion from the statements given, put a heavy black mark under "CONCLUSION DOES NOT FOL. LOW," even though you may believe it to be true from your general knowledge.

Likewise, read and judge each of the other conclusions. Try not to let your prejudices influence your judgment-just stick to the given statements (premises) and judge each conclusion as to whether it necessarily follows from them.

The word "some" in any of these statements means an indefinite part or quantity of a class of things. "Some". means at least a portion, and perhaps all of the class. Thus, "Some holidays are rainy" means at least one, possibly more than one, and perhaps even all holidays are rainy.

Study the example carefully before starting the test.

\section{EXAMPLE}

Some holldays are rainy. All rainy days are boring. Therefore-

1. No clear days are boring. (The conclusion does not follow. You cannot tell from the statements whether or not clcar daya are boring. Some may be.)

2. Some holldayl are boring. The conclusion necessarily follows from the statements since, according to them, the rainy bolldaya muat be boring.)

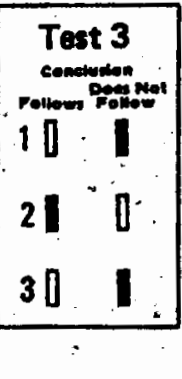

3. Some holidays are not boring. (The conclusion does not follow, even though you may know that some holldays are very pleasant.) 


\section{TEST 4: INTERPRETATION}

\section{DIRECTIONS}

Each exercise below consists of a short paragraph followed by several suggested conclusions.

For the purpose of this test, assume that everything in the short paragraph is true. The problem is to judge whether or not each of the proposed conclusions logically follows beyond a reasonable doubt from the information given in the paragraph.

If you think that the proposed conclusion follows beyond a reasonable doubt (even thougli it may not follow absolutely and necessarily), then make a heavy black mark under "CONCLUSION FOLLOWS" in the proper place on the answer sheet. If you think that the conclusion does not follow beyond a reasonable doubt from the facts given; then blacken the space under "CONCLUSION DOES NOT FOLLOW." Remember to judge each conclusión independently.

Look at the example below; the block at the right shows how the answers should be marked on the answer. sheet.

\section{EXAMPLE}

A study of vocabulary growth in children from eight months to six yeats. old shows that the dize of spoken vocabulaty increases from zero words at age eight months to 2562 words at age six years.

1. None of the children in this study had learned to talk by the age of six months.

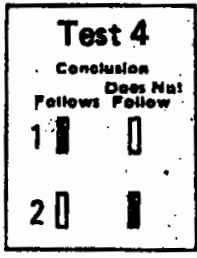
The conclution follows beyond a reasanable doubt aince. " according to the thatement, the siye of the opoken vocabulary at eight months was zero words.).

2 Vocabulary growth ts stowest during the period when children are learning to walk. (The concluiton does not follow since there is no information given that relátes growth of vocabulary to walking.)

\section{TEST 5: EVALUATION OF ARGUMENTS}

\section{DIRECTONS}

In making decisions about important questions, it is desirable to be able to distinguish between arguments that are strong and arguments that are weak, as far as the question at issue is concerned. For an argument to be strong, it must be both important and directly related to the question.

An argument is weak if it is not directly related to the question (even though it may be of great general importance), or if it is of minor importance, or if it is related only to trivial aspects of the question.

Below is a series of questions. Each question is followed by several arguments. For the purpose of this test, you are to regard each argument as true. The problem then is to decide whether it is a strong or a weak argument.

Make a heavy black mark on the answer sheet under "ARGUMENT STRONG" if you think the argument is strong, or under "ARGUMENT WEAK" if you think the argument is weak. Judge each argument separately on its own merit. Try not to let your personal attitude toward the question influence your evaluation of the argument, since each argument is to be regarded as true.

In the example, note that the argument is evaluated as to how well it supports the side of the question indicated.

\section{EXAMPLE}

Should all young men in the United States go to college?

1. Yes; college provides an opportunity for them to learn school songs and checrs. (This would be a silly reason for spending years in college.)

2. No; a large percent of young men do not have enough ability or interest to derive any benefit from college training. (If this is true, as the directions require us to assume, it is a weighty argument against all young men going to college.)

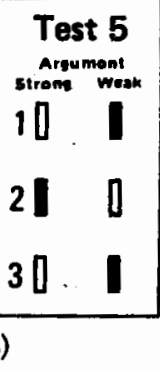

3. No; excessive studying permanently warps an individual's personality. (This argument, although of great general importance when accepted as true, is not directly related to the question, because attendance at college does not necessarily require excessive studying.) 


\section{APPENDIX G}

Sample Written Simulation Examination 
Study Guide for the

NATA

BOARD OF CERTIFICATION, INC.

Entry-Level

Athletic Trainer

THIRD EDITION 


\section{,}
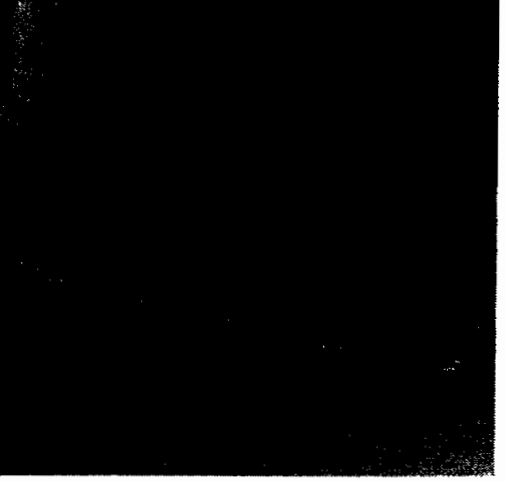

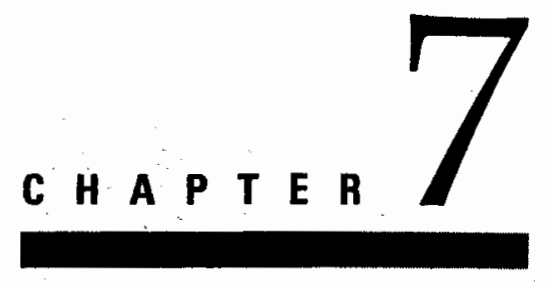

The

\section{Simulation} Examination

\section{SIMULATION EXAMINATION INFORMATION}

The problems in this section of the examination are designed to test your decision-making ability in athletic training. To take this section of the examination, you will need the latent-image pen and the Simulation Answer. Booklet. Although this study guide contains four sample simulation questions, the actual examination will have eight such problems. The correct answers and point values for each response are provided at the end of this chapter.

\section{Time Allowed}

You will have 2.5 hours to complete the simulation portion of the examination.

\section{Instructions}

Read the opening scene, which provides the introductory facts with which you will work. Read this situation, and all subsequent sections, carefully and follow the directions provided. Some sections ask for more than one response. Choose all responses that you believe are relevant to the circumstances given. If you fail to choose a response that should have been highlighted, you will not receive full credit for the section. Similarly, if you highlight a response that should not have been chosen, points will be deducted from your score.

In each section, choices appear in a random order. The response you choose will provide you with specific information and the results of your decisions, or it will provide you with specific instructions. Use the information and results to determine your course of action for the next section. If you are given additional instructions, follow them exactly. Failure to do so will result in deductions from your score and may make it impossible to complete the problem correctly.

\section{II $\operatorname{ll} \boldsymbol{l}$ ful II $i \| t \mathrm{~s}$}

If you are one of those individuals who reveals too much, start by revealing the answers that give you additional information (i.e., information answers) and not those that are "action items." Even if you know you are going to reveal more than one answer, reveal the "information items" first.

For example, if you do not know which to reveal first: "Take the athlete's pulse" or "Place the athlete on a backboard," then choose "Take the athlete's pulse" because that could give you more information about the scenario. Placing an athlete on a backboard (an action item) may also be necessary but more than likely will not give you additional information about the scenario.

Continue to work through the problems section by section until you uncover the response "End of Problem" with your. latent-image pen. Some problems may not contain this response. If not, it will be noted in the section instructions for that particular problem. When you uncover this response, do not go back into the problem and uncover additional responses. This is not likely to improve your score and may result in penalties. 


\section{Simulation Examination Sample Questions}

\section{Sample Problem 1}

\section{OPENING SCENE}

A volleyball player.has injured her left ankle during practice. You have completed your evaluation, and you suspect a moderate second-degree lateral ankle sprain.

\section{Go to Section $A$ \\ Section A}

Immediately after your evaluation, you will do which of the following? (Choose only those actions that you have reason to believe are essential to the resolution of the case.) '

1. Tape her ankle securely and see if she can finish practice.

2. Apply ice to the left ankle.

3. Have the athlete walk the injury off.

4. Write a note to excuse her from classes tomorrow.

5. Apply a compression wrap to the injured ankle.

\section{Go to Section $B$ \\ Section B}

Volleyball practice is over now, and you and the athlete are in the athletic training room. The amount of swelling has increased since you evaluated the injury, and the athlete cannot bear weight without pain. Indicate your actions at this time. (Choose only those actions that you have reason to believe are essential to the resolution of this case.)

6. Secure, measure, and instruct the athlete in the use of crutches.

7. Call the coach to tell her the swelling has increased.

8. Give the athlete a warm whirlpool treatment.

\section{Go to Section C}

\section{Section C}

The team physician sees the athlete and diagnoses the injury as a moderate second-degree lateral ankle sprain. The physician does not apply a splint or cast but instructs the athlete to continue using crutches as long as the weight bearing causes pain. The physician refers the athlete back to you with proper instructions. What action will you take next? (Choose only those actions that you have reason to believe are essential to the resolution of the case.)

9. Instruct the athlete to continue the ice treatments for the rest of the day until she goes to sleep.

10. Instruct the athlete to use a heating pad on her ankle while she sleeps.

11. Instruct the athlete to call the coach to tell her what the doctor said.

12. Uncover response 12.

End of Sample Problem 1 